\title{
Polymer, 2016
}

\section{A novel route for tethering graphene with iron oxide and its magnetic field alignment in polymer nanocomposites}

Shuying $\mathrm{Wu}^{\mathrm{a}}$, Jin Zhang ${ }^{\mathrm{b}}$, Raj B. Ladani ${ }^{\mathrm{a}}$, Kamran Ghorbani ${ }^{\mathrm{a}}$, Adrian P. Mouritz ${ }^{\mathrm{a}}$, Anthony J.

Kinloch $^{\mathrm{c}}$, and Chun H. Wang ${ }^{\mathrm{a}}$

a Sir Lawrence Wackett Aerospace Research Centre, School of Engineering, RMIT University, GPO Box 2476, Melbourne, VIC 3001, Australia

${ }^{\mathrm{b}}$ Australian Future Fibres Research and Innovation Centre, Institute for Frontier Materials, Deakin University, VIC 3220, Australia

${ }^{\mathrm{C}}$ Department of Mechanical Engineering, Imperial College London, London, SW7 2BX, U.K.

${ }^{*}$ Corresponding author. E-mail: chun.wang@rmit.edu.au, Tel: $\underline{+61399256115}$ 


\begin{abstract}
We present a new route for tethering graphene nanoplatelets (GNPs) with $\mathrm{Fe}_{3} \mathrm{O}_{4}$ nanoparticles to enable their alignment in an epoxy using a weak magnetic field. The GNPs are first stabilised in water using poly(vinylpyrrolidone) (PVP) and $\mathrm{Fe}_{3} \mathrm{O}_{4}$ nanoparticles are then attached via coprecipitation. The resultant $\mathrm{Fe}_{3} \mathrm{O}_{4} / \mathrm{PVP}-\mathrm{GNPs}$ nanohybrids are superparamagnetic and can be aligned in an epoxy resin, before gelation, by applying a weak magnetic field as low as $0.009 \mathrm{~T}$. A theoretical model describing the alignment process is presented. The resulting nanocomposites exhibit anisotropic properties with significantly improved electrical conductivities (three orders of magnitude) in the alignment direction and dramatically increased fracture energy (about 530\%) when the nanohybrids are aligned transverse to the crack growth direction, compared with the unmodified epoxy. Compared with the randomly-oriented nanocomposites, these aligned nanocomposites show approximately 50\% increase in toughness transverse to the alignment direction and a seven-fold increase in electrical conductivity in the alignment direction.
\end{abstract}

Keywords: Graphene platelets, Magnetic-field alignment, Epoxy nanocomposites, Fracture toughness, Electrical conductivity 


\section{Introduction}

Graphene-based polymer nanocomposites are a promising class of advanced materials with substantial enhancements in multifunctional properties at much lower loadings than polymer composites with conventional micron-scale fillers [1]. Recently, graphene-based hybrids, especially graphene-metal or metal-oxide nanoparticles hybrids have attracted considerable attention due to their ability to impart multifunctional properties to polymer nanocomposites [27]. The synergistic effects of graphene and functional nanoparticles may result in enhanced properties which favour their application in catalysis [5], energy storage [6], and electromagnetic wave absorption [7]. Magnetite nanoparticles $\left(\mathrm{Fe}_{3} \mathrm{O}_{4}\right)$ are one type of these functional nanoparticles and they show some attractive properties, including their magnetic properties, low toxicity, and biocompatibility. Therefore, $\mathrm{Fe}_{3} \mathrm{O}_{4}$ nanoparticles hold promise for developing graphene hybrids with magnetic functionality, enabling possible manipulation by external magnetic fields $[8,9]$.

Graphene nanohybrids with $\mathrm{Fe}_{3} \mathrm{O}_{4}$ nanoparticles have been fabricated by several methods [1013]. $\mathrm{Fe}_{3} \mathrm{O}_{4}$ nanoparticles are either covalently or non-covalently attached onto the graphene, which reduces the aggregation of $\mathrm{Fe}_{3} \mathrm{O}_{4}$ nanoparticles and the restacking of exfoliated graphene sheets. For example, Diagboya et al. [10] recently fabricated graphene oxide (GO) with covalently-bonded magnetite nanoparticles via the reaction between carboxylic groups on the GO surface and amine groups on the 3-aminopropyltriethoxysilane functionalized $\mathrm{Fe}_{3} \mathrm{O}_{4}$. $\mathrm{He}$ et al. [11] synthesized $\mathrm{Fe}_{3} \mathrm{O}_{4}$ /graphene through a one-step reaction which reduced the $\mathrm{GO}$ and simultaneously produced $\mathrm{Fe}_{3} \mathrm{O}_{4}$ nanoparticles on the graphene sheets. Defect sites on the surface, or next to edges of the GO, are known anchoring sites to stabilize the $\mathrm{Fe}_{3} \mathrm{O}_{4}$ nanoparticles [12]. 
Therefore, GO is the most commonly used precursor to produce $\mathrm{Fe}_{3} \mathrm{O}_{4} /$ graphene nanohybrids. However, the subsequent reduction of the GO usually weakens the interactions between these two components. Also, the reduction of the GO is usually incomplete and some oxygencontaining functional groups may therefore remain on the graphene sheets [13]. It is thus expected that directly attaching $\mathrm{Fe}_{3} \mathrm{O}_{4}$ nanoparticles to graphene, instead of GO, should enable fabrication of magnetic $\mathrm{Fe}_{3} \mathrm{O}_{4}$ /graphene, whilst retaining the exceptional properties of the graphene. However, little work has been reported on the non-covalent attachment of $\mathrm{Fe}_{3} \mathrm{O}_{4}$ nanoparticles directly onto graphene nanoplatelets.

Polymeric nanocomposites based on carbon nanomaterials (such as graphene, carbon nanotubes, etc.) have attracted considerable interest due to the significantly improved properties that may be attained $[14,15]$. However, the full potential of carbon nanomaterials is yet to be realized due to difficulties of dispersing and aligning such additives in polymers [16-18]. Recently, it was reported that an electric field can be employed to align carbon nanotubes (CNTs) [19, 20], carbon nanofibres (CNFs) [21, 22] and graphene nanoplatelets (GNPs) [23], with the resulting polymeric nanocomposites exhibiting significantly improved fracture toughness and electrical conductivity compared with their randomly-oriented counterparts. The application of a magnetic field is also as an effective way to align carbon nanomaterials in polymers. For instance, a magnetic field up to $25 \mathrm{~T}$ has been shown to be capable of aligning carbon nanotubes in epoxy resin, resulting in epoxy polymer nanocomposites with superior mechanical properties compared with those prepared in the absence of a magnetic field [24]. Nevertheless, due to the low magnetic susceptibility of carbon nanomaterials, a relatively high magnetic field is usually required which greatly limits its practical applications. However, we [25] have shown that the 
attachment of $\mathrm{Fe}_{3} \mathrm{O}_{4}$ nanoparticles can greatly enhance the magnetic susceptibility of CNFs, allowing the $\mathrm{Fe}_{3} \mathrm{O}_{4} / \mathrm{CNFs}$ to be aligned in the epoxy before it cures, using a weak magnetic field (i.e. $0.05 \mathrm{~T}$ ). The resulting epoxy polymer nanocomposites were found to possess a greatly improved fracture toughness [25]. However, the alignment of graphene in polymers using a magnetic field has not been extensively investigated.

Recently, Wajid et al. [26] demonstrated that poly(vinylpyrrolidone) (PVP) can act as a stabilizer to enable graphene to be dispersed in a wide range of solvents through non-covalent bonding to the graphene basal plane. They also demonstrated that PVP-grafted $\mathrm{Fe}_{3} \mathrm{O}_{4}$ can be used in a similar role as a dispersant to stabilize graphene in water, leading to magnetic $\mathrm{Fe}_{3} \mathrm{O}_{4} /$ graphene nanohybrids [13]. Nevertheless, in spite of these discoveries, the alignment of the resultant $\mathrm{Fe}_{3} \mathrm{O}_{4} /$ graphene nanohybrids in a polymer using a magnetic field has not been explored.

Thus, in the present work, we describe a new method of non-covalently tethering graphene nanoplatelets with $\mathrm{Fe}_{3} \mathrm{O}_{4}$ nanoparticles, with the assistance of PVP. The $\mathrm{Fe}_{3} \mathrm{O}_{4}$ nanoparticles are attached to the PVP-stabilized graphene nanoplatelets (PVP-GNPs) via co-precipitation. Alignment of the resulting nanohybrids (denoted by $\mathrm{Fe}_{3} \mathrm{O}_{4} / \mathrm{PVP}-\mathrm{GNPs}$ ) under a relatively weak magnetic field in an epoxy resin is investigated experimentally and theoretically. The key parameters controlling the alignment are identified based on the proposed theoretical model. The fracture energy and electrical conductivity of the epoxy polymer nanocomposites arising from the addition of the $\mathrm{Fe}_{3} \mathrm{O}_{4} / \mathrm{PVP}-\mathrm{GNPs}$, both randomly-oriented and aligned, are measured and compared. Finally, the toughening mechanisms are identified from fractographic studies. To our knowledge, this is the first study which investigates the effects of aligning $\mathrm{Fe}_{3} \mathrm{O}_{4} / \mathrm{PVP}-\mathrm{GNPs}$ 
nanohybrids via a weak magnetic field to improve the mechanical and electrical properties of polymeric nanocomposites.

\section{Materials and methods}

\subsection{Materials}

Iron (II) sulfate heptahydrate $\left(\mathrm{FeSO}_{4} \cdot 7 \mathrm{H}_{2} \mathrm{O}\right)$, anhydrous iron chloride $\left(\mathrm{FeCl}_{3}\right)$, ammonia hydroxide $\left(\mathrm{NH}_{4} \mathrm{OH}\right)$, and poly(vinylpyrrolidone) (PVP) $\left(\mathrm{M}_{\mathrm{w}} \sim 10,000\right)$ were sourced from SigmaAldrich, Australia. The GNPs used in the present study were obtained from XG Science, having an average thickness of approximately 1-20 nm and an average particle diameter of $25 \mu \mathrm{m}$. The liquid epoxy resin ('105’) and hardener ('206') were supplied by WEST SYSTEM ${ }^{\circledR}$. The composite substrates were manufactured from T700 carbon-fibre/epoxy prepreg ('VTM 264') supplied by Applied Composites Group, and the details can be found in our previous work [22, $23,25]$.

\subsection{Preparation of the $\mathrm{Fe}_{3} \mathrm{O}_{4} / \mathrm{PVP}$-GNPs nanohybrids}

To synthesize the $\mathrm{Fe}_{3} \mathrm{O}_{4}$ /PVP-GNPs nanohybrids, an aqueous dispersion of GNPs was first prepared using PVP. The PVP was dissolved in water to produce a $10 \mathrm{mg} / \mathrm{mL}$ aqueous solution, to which the as-received GNPs (20 mg/mL) were added. After being magnetically stirred for 10 minutes, the solution was sonicated in an ice bath for $1 \mathrm{~h}$ using a Hielscher UP200S ultrasonic homogenizer operated at 0.5 cycles and $40 \%$ amplitude. The dispersions so obtained were then centrifuged at $4400 \mathrm{rpm}$ for $1 \mathrm{~h}$. This led to relatively large aggregates of GNPs separating out as sediment, and the supernatant liquid, termed PVP-GNPs, was retained. 
The supernatant liquid, obtained as described above, was used as the starting material to synthesize $\mathrm{Fe}_{3} \mathrm{O}_{4} / \mathrm{PVP}$-GNPs nanohybrids by a facile co-precipitation method under a nitrogen atmosphere using a 1:2 mol ratio of $\mathrm{Fe}^{2+}$ and $\mathrm{Fe}^{3+}$ [25, 27]. Firstly, $200 \mathrm{~mL}$ of the aqueous dispersion of PVP-GNPs was mixed with $0.225 \mathrm{~g}$ of $\mathrm{FeCl}_{3}$ and $0.18 \mathrm{~g}$ of $\mathrm{FeSO}_{4} .7 \mathrm{H}_{2} \mathrm{O}$ under vigorous stirring whilst being purged with $\mathrm{N}_{2}$ gas to remove the dissolved oxygen. After about 15 minutes, the mixture was heated to $50{ }^{\circ} \mathrm{C}$. Secondly, $15 \mathrm{~mL}$ of an aqueous solution of $8 \mathrm{M}$ $\mathrm{NH}_{4} \mathrm{OH}$ was added drop-wise to precipitate ferric and ferrous salts. The $\mathrm{pH}$ value of the mixture was kept at $\sim 10$ and the reaction was carried out at $50{ }^{\circ} \mathrm{C}$ for 45 minutes under vigorous stirring. Finally, the $\mathrm{Fe}_{3} \mathrm{O}_{4}$ /PVP-GNPs nanohybrids were obtained by magnetic separation, washed with distilled water and ethanol, and dried under vacuum at $50{ }^{\circ} \mathrm{C}$.

\subsection{Preparation of epoxy nanocomposites with $\mathrm{Fe}_{3} \mathrm{O}_{4} / \mathrm{PVP}-\mathrm{GNPs}$ nanohybrids}

The epoxy nanocomposites containing the $\mathrm{Fe}_{3} \mathrm{O}_{4} / \mathrm{PVP}-\mathrm{GNPs}$ nanohybrids were prepared via solution-blending. The nanohybrids were firstly dispersed in acetone using sonication for 15 minutes. The epoxy resin was then added and the sonication process was continued for $1 \mathrm{~h}$. The acetone was removed using a vacuum oven, leading to an epoxy resin containing $\mathrm{Fe}_{3} \mathrm{O}_{4} / \mathrm{PVP}-$ GNPs. After mixing with a stoichiometric amount of hardener and degassing, which took 15 minutes, a weak magnetic field of $\sim 0.02 \mathrm{~T}$ generated by a pair of permanent magnets, was applied to align the nanohybrids. This magnetic field strength was selected based on the theoretical modelling calculations discussed in Section 3.2.1, such that alignment of the nanohybrids would be completed prior to gelation of the epoxy resin. The epoxy mixtures were

cured at room temperature $\left(25{ }^{\circ} \mathrm{C}\right)$ for $48 \mathrm{~h}$. Epoxy polymer nanocomposites containing $0.5 \mathrm{wt} \%$ 
and $1.0 \mathrm{wt} \%$ of randomly-oriented or nanohybrids aligned in the in-plane and/or out-of-plane direction were prepared.

\subsection{Characterization}

\subsubsection{Characterization of $\mathrm{Fe}_{3} \mathrm{O}_{4} / \mathrm{PVP}-\mathrm{GNPs}$}

The morphology of the nanohybrids was investigated using a JEOL 2010 Transmission Electron Microscope (TEM) operated at $100 \mathrm{kV}$. An ethanol dispersion of the nanohybrids was deposited onto a copper grid for TEM investigation. Scanning electron microscopy (SEM) analysis was performed using a FEI Nova NanoSEM equipped with an Oxford X-MaxN 20 energy dispersive X-ray (EDX) detector, operated at $15 \mathrm{kV}$ and a $5 \mathrm{~mm}$ working distance. X-ray diffraction (XRD) patterns of the samples were collected using a Bruker D8 Advance diffractometer using $\mathrm{Cu}-\mathrm{K} \alpha$ radiation $(\lambda=1.54 \AA)$. X-ray photoelectron spectroscopy (XPS) was performed using a Thermo K-alpha XPS instrument at a pressure of $\sim 1 \times 10^{-9}$ Torr with the core levels aligned with the C 1s binding energy of $284.8 \mathrm{eV}$. Magnetic hysteresis loops were measured at room temperature (300 K) using a Quantum Design MPMS-5 DC-SQUID (superconducting quantum interference device) susceptometer. Thermogravimetric analysis (TGA) data were collected using a PerkinElmer Thermogravimetric Analyzer under an air atmosphere at a heating rate of $10{ }^{\circ} \mathrm{C} \min ^{-1}$.

\subsubsection{Characterization of epoxy nanocomposites}

The values of the mode-I fracture energy, $\mathrm{G}_{\mathrm{Ic}}$, of the epoxy nanocomposites were obtained from double cantilever beam (DCB) tests on carbon-fibre composite joints bonded employing the epoxy nanocomposites. Details of the procedure for manufacturing the composite joints were reported in our previous work [25]. The load was applied to the specimens at a crosshead speed 
of $1 \mathrm{~mm} / \mathrm{min}$ in accordance with ISO 25217. The values of $\mathrm{G}_{\text {Ic }}$ were calculated based on the “corrected beam theory” method [28]. The load versus displacement curves for the epoxy nanocomposites revealed that the specimens exhibited unstable, 'stick-slip' crack growth. The average value of the maximum load peaks was taken to deduce the value of $\mathrm{G}_{\text {Ic }}$ for the onset of crack growth. The first peak of the load versus displacement curve was ignored to ensure that only subsequent values of the maximum loads, which were associated with crack initiation from relatively sharp, 'natural', cracks, were used to calculate $\mathrm{G}_{\mathrm{Ic}}$. At least five replicate specimens were tested for each formulation. The electrical conductivity of the cured joints was measured using a high-resistance meter (Model HR2) in the direction normal to the substrate surfaces, i.e. in the through-thickness direction. Rheological measurements of the viscosity of the epoxy resin mixed with the hardener, as a function of time, were performed using a TA Discovery Hybrid Rheometer which had parallel-plate test geometry. The plate diameter and its gap are $40 \mathrm{~mm}$ and $0.75 \mathrm{~mm}$ respectively. Measurements were carried out with an angular frequency of $1 \mathrm{~Hz}$ and an initial strain of $10 \%$.

\section{Results and discussion}

\subsection{Characterization of $\mathrm{Fe}_{3} \mathrm{O}_{4} / \mathrm{PVP}-\mathrm{GNPS}$}

\subsubsection{Morphology and chemical properties}

Fig. 1 illustrates the procedure used to produce the $\mathrm{Fe}_{3} \mathrm{O}_{4} / \mathrm{PVP}-\mathrm{GNPs}$. To disperse the GNPs and obtain a stable aqueous dispersion, PVP was used as a stabilizer which can be non-covalently bonded to the basal plane of graphene platelets without creating defects [13, 26]. The iron precursors $\left(\mathrm{Fe}^{3+} / \mathrm{Fe}^{2+}\right)$ were coordinated to the carbonyl groups present on the PVP and the GNPs. 
Upon addition of ammonium hydroxide, $\mathrm{Fe}_{3} \mathrm{O}_{4}$ nanoparticles gradually grew at these sites, as verified by the XPS results shown later in the present section.

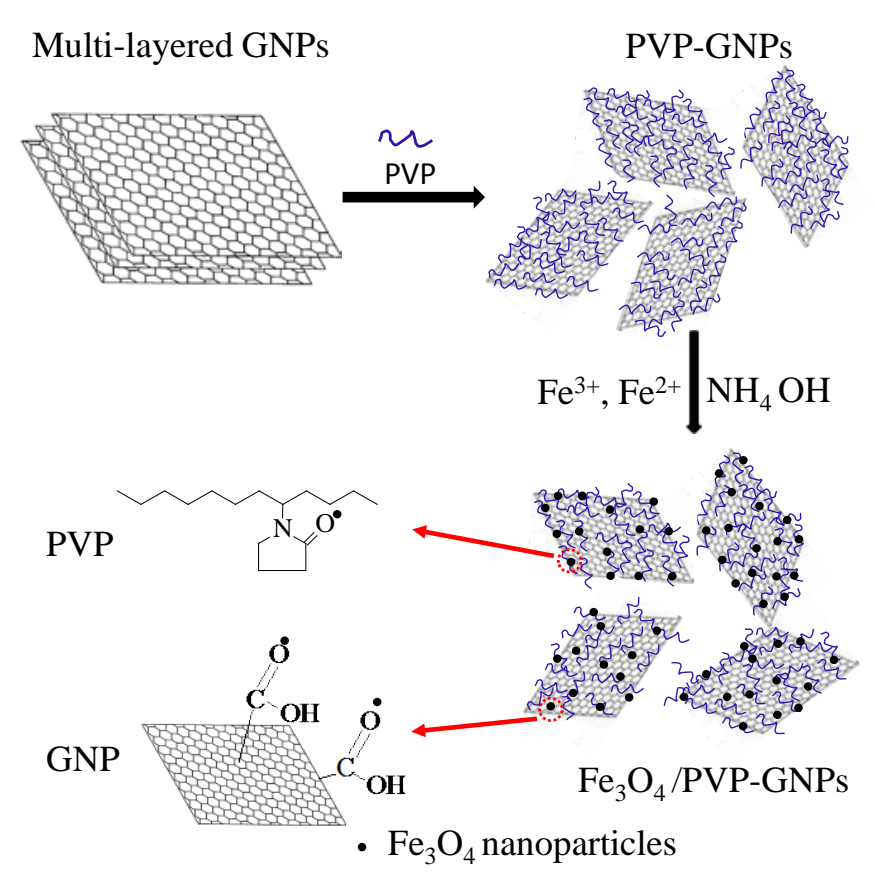

Fig. 1. Schematic illustration of the formation of the $\mathrm{Fe}_{3} \mathrm{O}_{4} / \mathrm{PVP}-\mathrm{GNPs}$ nanohybrids.

Fig. 2a shows a typical TEM image of PVP-GNPs, and it is seen that the PVP-GNPs are a few layers thick. This is consistent with the results reported by Wajid et al. [26], indicating that PVP is able to facilitate the dispersion and exfoliation of GNPs in water. A TEM image of the $\mathrm{Fe}_{3} \mathrm{O}_{4} /$ PVP-GNPs (Fig. 2b) reveals that the GNPs are densely covered by $\mathrm{Fe}_{3} \mathrm{O}_{4}$ nanoparticles. The lattice fringe spacing is $0.25 \mathrm{~nm}$, as indicated in the high resolution transmission electron microscopy (HRTEM) image (Fig. 2c). This spacing value is in good agreement with the lattice spacing of the (311) planes of cubic magnetite. The average diameter of the $\mathrm{Fe}_{3} \mathrm{O}_{4}$ particles is calculated to be $\sim 11.9 \mathrm{~nm}$ and the size distribution is given in Fig. 2d, which is based on Fig. $\mathbf{2 b}$. The morphology of the $\mathrm{Fe}_{3} \mathrm{O}_{4} / \mathrm{PVP}$-GNPs was also investigated using SEM (Fig. 2e). It can be 
clearly seen that the GNPs are covered with $\mathrm{Fe}_{3} \mathrm{O}_{4}$ nanoparticles. The majority of $\mathrm{Fe}_{3} \mathrm{O}_{4}$ nanoparticles are uniformly distributed on the GNPs although some clustering of the nanoparticles is observed. The composition of the nanohybrids was measured using EDX and the spectrum is shown in Fig. 2f, confirming the presence of Fe and O elements. 

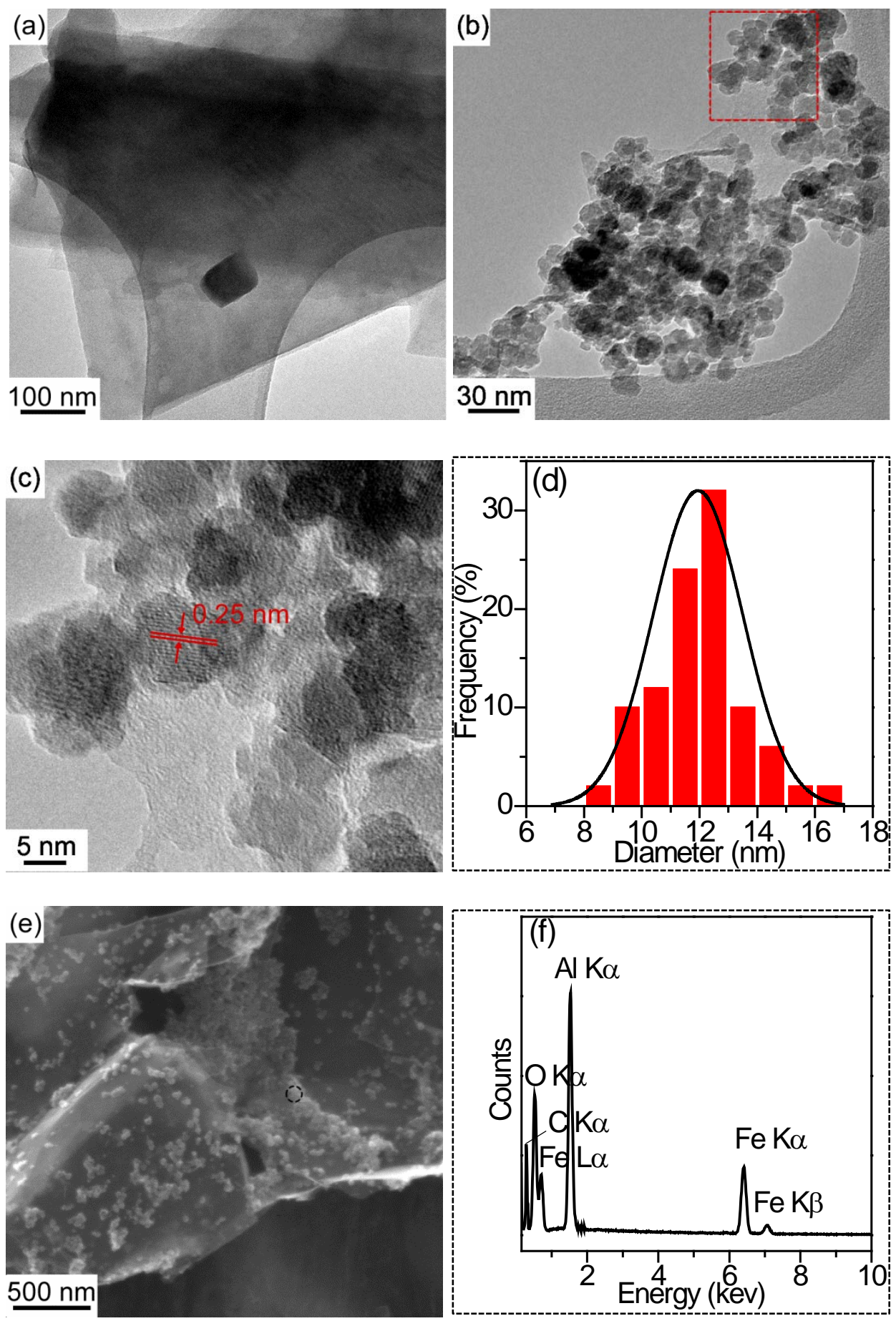

Fig. 2. TEM images of (a) PVP-GNPs, (b) and (c) $\mathrm{Fe}_{3} \mathrm{O}_{4} / \mathrm{PVP}-\mathrm{GNPs}$; (d) size distribution analysis of the $\mathrm{Fe}_{3} \mathrm{O}_{4}$ nanoparticles ( 80 nanoparticles in (b) were taken into account); (e) SEM image of $\mathrm{Fe}_{3} \mathrm{O}_{4}$ /PVP-GNPs; (f) EDX spectrum from the point indicated by the 'circle' in the 
SEM image shown in (e). Note (c) is the magnified image taken from the rectangular region in (b).

Fig. 3 shows XRD patterns of the as-received GNPs and the $\mathrm{Fe}_{3} \mathrm{O}_{4} / \mathrm{PVP}-\mathrm{GNPs}$. A strong diffraction peak is observed at $\sim 26.6^{\circ}$ in the XRD spectrum of the GNPs which can be attributed to the (002) plane of the graphite structure [25]. The XRD pattern of the as-synthesized $\mathrm{Fe}_{3} \mathrm{O}_{4} / \mathrm{PVP}$-GNPs exhibits characteristic XRD peaks of both the GNPs and iron oxide. The main characteristic XRD peaks of iron oxide are located at $2 \theta=30.5^{\circ}, 35.9^{\circ}, 43.0^{\circ}, 53.6^{\circ}, 57.3^{\circ}$, and $62.8^{\circ}$ and they respectively correspond to the (220), (311), (400), (422), (511), and (440) planes of maghemite $\left(\gamma-\mathrm{Fe}_{2} \mathrm{O}_{3}\right)$ and/or magnetite $\left(\mathrm{Fe}_{3} \mathrm{O}_{4}\right)$ [25, 29]. To identify the maghemite and magnetite, XPS was employed and the results are discussed below.

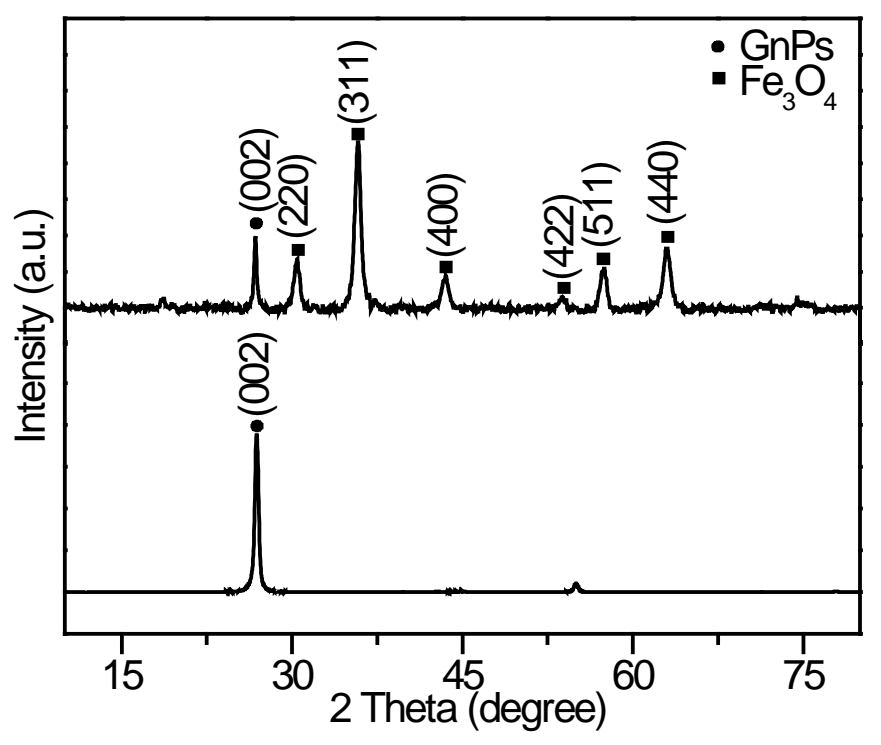

Fig. 3. XRD patterns of as-received GNPs and the $\mathrm{Fe}_{3} \mathrm{O}_{4} / \mathrm{PVP}-\mathrm{GNPs}$ nanohybrids.

Fig. 4a gives the C1s spectra of the as-received GNPs and PVP, PVP-GNPs, and $\mathrm{Fe}_{3} \mathrm{O}_{4} / \mathrm{PVP}-$ GNPs. The spectra of the as-received GNPs is composed of C and O with a ratio of C:O of 
93:7. The C1s peak can be deconvoluted into three components: peak 1 at $284.6 \mathrm{eV}$ corresponding to non-oxygenated carbon $(\mathrm{C}=\mathrm{C} / \mathrm{C}-\mathrm{C})$ in aromatic rings (76.2 at\%); peak 2 at $285.6 \mathrm{eV}$ corresponding to C-O-C/C-OH (22.8 at\%); and peak 3 at $~ 288.1 \mathrm{eV}$ corresponding to carboxyl $\mathrm{C}=\mathrm{O} / \mathrm{O}-\mathrm{C}=\mathrm{O}(1 \mathrm{at} \%)$. The $\mathrm{C} 1 \mathrm{~s}$ peak of the as-received PVP shows similar peaks at 284.9 eV (“peak a”) and 285.9 eV (“peak b”) corresponding to C-C and C-N, respectively. Another peak at $287.4 \mathrm{eV}$ ("peak c") is attributed to $\mathrm{N}-\mathrm{C}=\mathrm{O}$ [30]. For the PVP-GNPs, the characteristic peaks of both PVP and GNPs remain nearly unchanged, which indicates that the chemical environment associated with the carbon atom is unchanged.

The XPS survey spectrum (Fig. 4b) of the $\mathrm{Fe}_{3} \mathrm{O}_{4} / \mathrm{PVP}-\mathrm{GNPs}$ confirms the presence of iron. The high-resolution Fe2p spectrum of $\mathrm{Fe}_{3} \mathrm{O}_{4} / \mathrm{PVP}-\mathrm{GNPs}$ is shown in Fig. 4c. The binding energy peaks at $\sim 710.9$ and $724.6 \mathrm{eV}$ correspond to Fe2p1/2 and 2p3/2, respectively, which is consistent with previously reported values for $\mathrm{Fe}_{3} \mathrm{O}_{4}[11,25]$. A very small shoulder exists at $\sim 719.1 \mathrm{eV}$, indicating the possible presence of a relatively low concentration of $\gamma-\mathrm{Fe}_{2} \mathrm{O}_{3}$. The interfacial interaction between the $\mathrm{Fe}_{3} \mathrm{O}_{4}$ nanoparticles and the graphene nanoplatelets are associated with the preparation methods and can be covalent, non-covalent, electrostatic interactions, etc. [31]. The $\mathrm{Fe}_{3} \mathrm{O}_{4}$ nanoparticles can be attached to the GNPs directly by forming Fe-C bonds or Fe-O-C bonds or by using some organic molecular chains [11, 13, 31]. The possible bonds between $\mathrm{Fe}_{3} \mathrm{O}_{4}$ and GNPs were investigated by fitting the C1s peak of the $\mathrm{Fe}_{3} \mathrm{O}_{4} /$ PVP-GNPs (Fig. 4a). The binding energy of the $\mathrm{O}-\mathrm{C}=\mathrm{O}$ group of the GNPs and $\mathrm{N}-\mathrm{C}=\mathrm{O}$ group of the PVP was shifted to higher binding energies, whilst the binding energies of the other peaks remained almost unchanged. These observations indicate that the $\mathrm{Fe}_{3} \mathrm{O}_{4}$ nanoparticles are connected to the PVP- 
GNPs through interacting with the $\mathrm{N}-\mathrm{C}=\mathrm{O}$ groups of the $\mathrm{PVP}$ and the $\mathrm{O}-\mathrm{C}=\mathrm{O}$ groups present on the GNP surfaces.
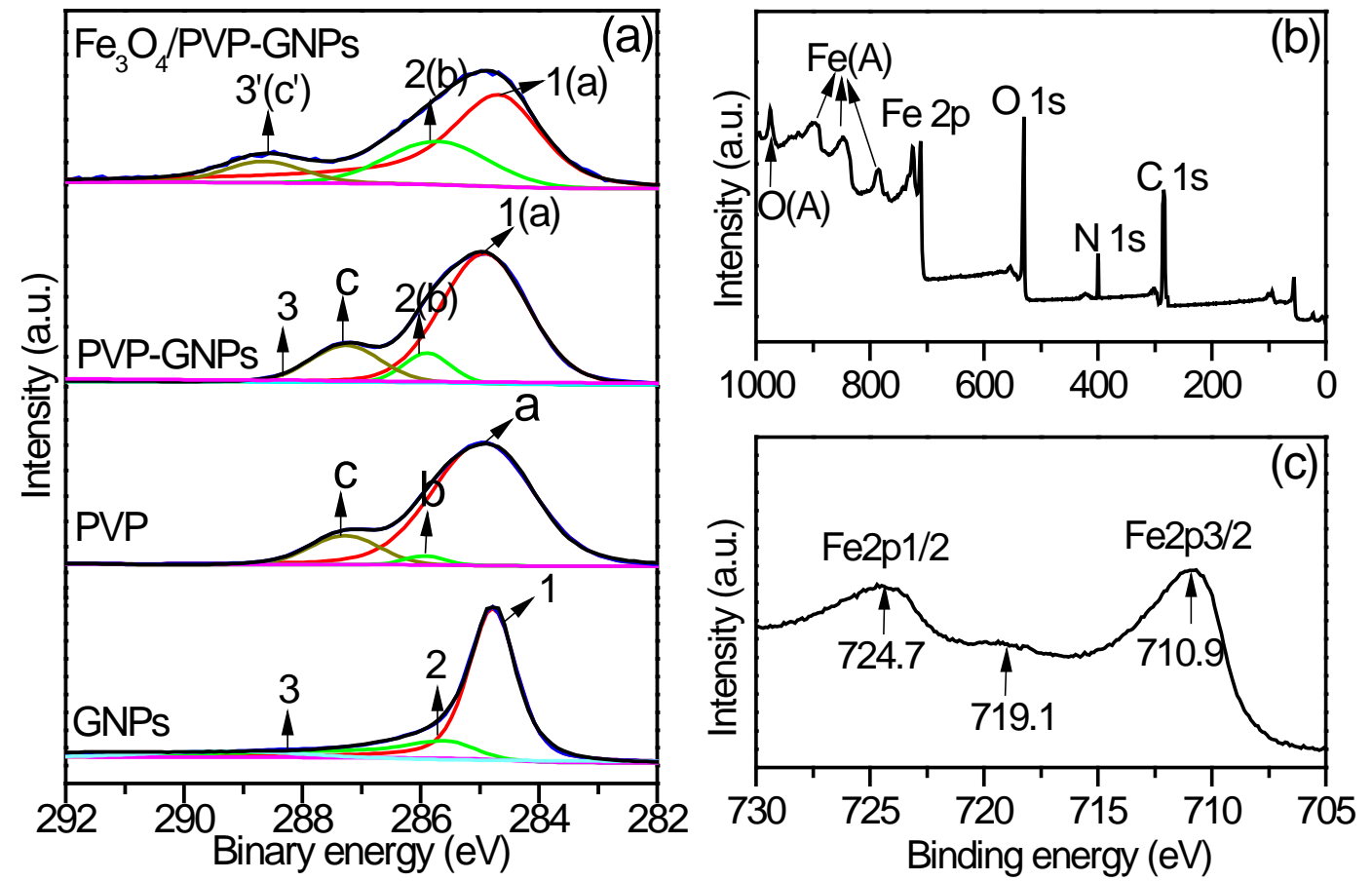

Fig. 4. XPS spectra: (a) high resolution C1s scans of the as-received GNPs and PVP, PVP-GNPs and $\mathrm{Fe}_{3} \mathrm{O}_{4}$ /PVP-GNPs nanohybrids; (b) survey spectrum of the $\mathrm{Fe}_{3} \mathrm{O}_{4}$ /PVP-GNPs ; (c) high resolution Fe2p scan of the $\mathrm{Fe}_{3} \mathrm{O}_{4} / \mathrm{PVP}-\mathrm{GNPs}$ nanohybrids.

TGA tests were performed to quantify the weight percentage of $\mathrm{Fe}_{3} \mathrm{O}_{4}$ in the nanohybrids and the weight loss curves are shown in Fig. 5. For PVP, the weight loss below $150{ }^{\circ} \mathrm{C}$ is attributed to the evaporation of physically-absorbed water. Significant weight loss is observed at $\sim 400{ }^{\circ} \mathrm{C}$ which results from the intra- and inter-molecular decomposition of PVP [32]. No weight loss is detected above $680{ }^{\circ} \mathrm{C}$, which indicates that the PVP is completely decomposed at this temperature. For the GNPs, no weight loss below $200{ }^{\circ} \mathrm{C}$ was observed, indicating that a negligible concentration of labile oxygen-containing functional groups are present [33]. Two 
abrupt weight losses occur at $\sim 400{ }^{\circ} \mathrm{C}$ and $700{ }^{\circ} \mathrm{C}$ due to carbonization. By increasing the temperature from room temperature to $800{ }^{\circ} \mathrm{C}$ in air, the $\mathrm{Fe}_{3} \mathrm{O}_{4}$ is oxidized to $\mathrm{Fe}_{2} \mathrm{O}_{3}$ and the GNPs are decomposed to $\mathrm{CO}$ and $\mathrm{CO}_{2}$. Theoretically, a weight increase of $3.45 \%$ is expected due to the reaction with $\mathrm{O}_{2}$ to form $\mathrm{Fe}_{2} \mathrm{O}_{3}[6,34]$. From the remaining weight, it is estimated that there is $\sim 55 \mathrm{wt} \%$ of $\mathrm{Fe}_{3} \mathrm{O}_{4}$ present on the $\mathrm{Fe}_{3} \mathrm{O}_{4} / \mathrm{PVP}-\mathrm{GNPs}$ nanohybrids.

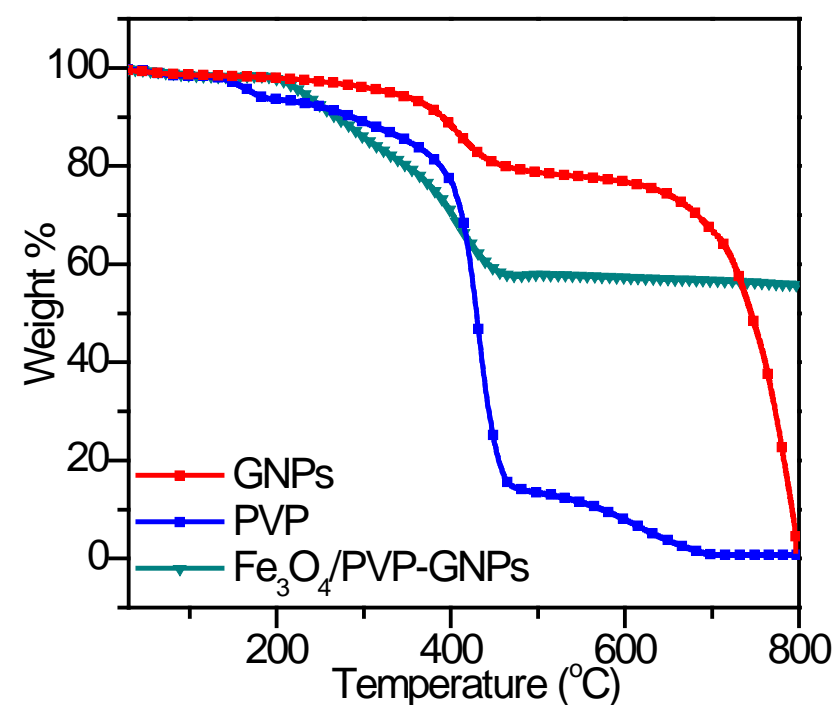

Fig. 5. TGA curves of the as-received GNPs, PVP and the $\mathrm{Fe}_{3} \mathrm{O}_{4} / \mathrm{PVP}-\mathrm{GNPs}$ nanohybrids.

\subsubsection{Magnetic properties}

Fig. 6a shows magnetic hysteresis loops for the $\mathrm{Fe}_{3} \mathrm{O}_{4} / \mathrm{PVP}-\mathrm{GNPs}$ nanohybrids measured at 300 K. The magnetization curves of both $\mathrm{Fe}_{3} \mathrm{O}_{4}$ and $\mathrm{Fe}_{3} \mathrm{O}_{4} /$ PVP-GNPs are 'S-like' curves where the magnetic remanence (i.e. the 'y intercept') is nearly zero, indicating a superparamagnetic behaviour. The saturation magnetization of the $\mathrm{Fe}_{3} \mathrm{O}_{4}$ nanoparticles is $67 \mathrm{emu} / \mathrm{g}$ which is comparable to the values reported previously [13, 35-37]. For the $\mathrm{Fe}_{3} \mathrm{O}_{4} / \mathrm{PVP}-\mathrm{GNPs}$, a lower saturation magnetization of $45 \mathrm{emu} / \mathrm{g}$ is observed, compared with that of the corresponding $\mathrm{Fe}_{3} \mathrm{O}_{4}$ nanoparticles. This is due to a decrease in the concentration of the magnetic component in 
the nanohybrids. However, this value of 45 emu $\mathrm{g}^{-1}$ is relatively higher than that of the $\mathrm{Fe}_{3} \mathrm{O}_{4}$ rGO obtained in previous work [36, 38], indicating a relatively high level of coverage of the $\mathrm{Fe}_{3} \mathrm{O}_{4}$ nanoparticles. The magnetic property of the $\mathrm{Fe}_{3} \mathrm{O}_{4} / \mathrm{PVP}-\mathrm{GNPs}$ is also revealed by placing a magnet next to an aqueous dispersion of the $\mathrm{Fe}_{3} \mathrm{O}_{4} / \mathrm{PVP}-\mathrm{GNPs}$. Indeed, it is shown in Fig. $\mathbf{6 b}$ that the $\mathrm{Fe}_{3} \mathrm{O}_{4} /$ PVP-GNPs can be completely attracted to the magnet.
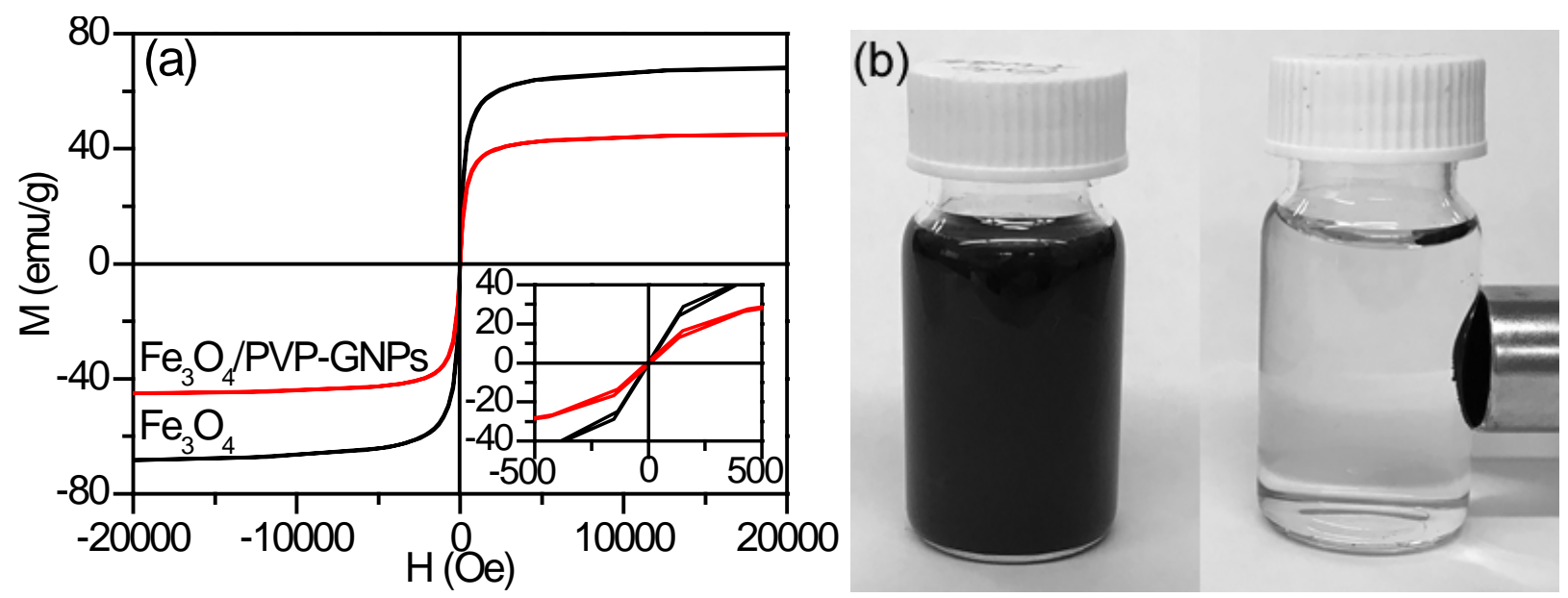

Fig. 6. (a) The magnetic hysteresis loops of $\mathrm{Fe}_{3} \mathrm{O}_{4}$ and the $\mathrm{Fe}_{3} \mathrm{O}_{4} / \mathrm{PVP}-\mathrm{GNPs}$ nanohybrids; (b) photographs of the $\mathrm{Fe}_{3} \mathrm{O}_{4}$ /PVP-GNPs nanohybrids in water before (left) and after (right) being exposed to a magnet.

\subsection{Alignment of the $\mathrm{Fe}_{3} \mathrm{O}_{4} / \mathrm{PVP}-\mathrm{GNPs}$ Nanohybrids}

\subsubsection{Theoretical studies on the unreacted system}

The alignment of the $\mathrm{Fe}_{3} \mathrm{O}_{4}$ /PVP-GNPs nanohybrids in liquid epoxy resin when exposed to an external magnetic field was investigated theoretically. When subjected to an external magnetic field, the magnetic moments exerted on the $\mathrm{Fe}_{3} \mathrm{O}_{4}$ nanoparticles force the $\mathrm{Fe}_{3} \mathrm{O}_{4}$ /PVP-GNPs nanohybrids to align in the direction of the magnetic field. The magnetic torque, $T_{m}$, can be 
calculated by considering GNPs as thin oblate spheroids with semi-major and semi-minor axes of $a$ and $b$, which correspond to the radius and half thickness of a GNP [39]:

$T_{m}=\frac{2 \pi \mu_{0} \chi_{n h}^{2}}{3\left(\chi_{n h}+1\right)}\left[(b+d)(a+d)^{2}-b a^{2}\right] H^{2} \sin 2 \theta$

where $\mu_{0}$ is the magnetic permeability of free space, $d$ is the diameter of the $\mathrm{Fe}_{3} \mathrm{O}_{4}$ nanoparticles, $H$ is the external magnetic-field strength, $\theta$ represents the angle between the magnetic field vector and the platelet's long axis, $\chi_{\text {nh }}$ is the magnetic susceptibility of the $\mathrm{Fe}_{3} \mathrm{O}_{4} / \mathrm{PVP}$-GNPs which is a function of the magnetic susceptibility of the $\mathrm{Fe}_{3} \mathrm{O}_{4}$ nanoparticles and their volume fraction. During rotation, the GNPs experience a viscous drag from the surrounding liquid resin. The viscous torque, $T_{\mathrm{v}}$, is proportional to the angular frequency of the platelet $\dot{\theta}$ and the viscosity of the fluid medium $\eta$ :

$T_{v}=\eta \dot{\theta} k_{r}$

where $k_{r}$ is the rotational friction coefficient and $k_{r}=32 a^{3} / 3$ [40]. The dynamics of the $\mathrm{Fe}_{3} \mathrm{O}_{4} / \mathrm{PVP}-\mathrm{GNPs}$ are determined by a balance between the magnetic torque and the viscous torque:

$T_{m}+T_{v}=0$

which yields:

$\dot{\theta}=-A \sin 2 \theta$

where $A=\frac{\pi \mu_{0} \chi_{n h}^{2}}{16 \eta\left(\chi_{n h}+1\right) a^{3}}\left[(b+d)(a+d)^{2}-b a^{2}\right] H^{2}$.

Thus the time, denoted as $t_{r}$, to rotate a $\mathrm{Fe}_{3} \mathrm{O}_{4} / \mathrm{PVP}$-GNPs from an initial angle $\theta_{1}$ to a generic angular position of $\theta_{2}$, can be determined from:

$t_{r}=\frac{1}{2 A} \ln \frac{\tan \theta_{1}}{\tan \theta_{2}}$ 
To estimate the time required for the $\mathrm{Fe}_{3} \mathrm{O}_{4} / \mathrm{PVP}-\mathrm{GNPs}$ to rotate, the final angle was set at a value slightly greater than $0^{\circ}$, i.e. $1.0^{\circ}$, otherwise the calculated time approaches an infinite value. The following values were used for the calculation: $2 a=25 \mu \mathrm{m}, 2 b=20 \mathrm{~nm}, \eta=1.6 \mathrm{~Pa} \cdot \mathrm{s}$ (initial viscosity), $\mu_{\mathrm{o}} \approx 1.2567 \times 10^{-6} \mathrm{~A} / \mathrm{m}$. The volume magnetic susceptibility of $\mathrm{Fe}_{3} \mathrm{O}_{4} / \mathrm{PVP}-\mathrm{GNPs}$ $\left(\chi_{n h}\right)$ was estimated to be $\sim 0.78$ (i.e. the initial slope of the hysteresis loop shown in Fig. 6). By solving Eq. (5) it is found that a minimum magnetic-field strength of $\sim 0.009 \mathrm{~T}$ is required to rotate a $\mathrm{Fe}_{3} \mathrm{O}_{4} / \mathrm{PVP}-\mathrm{GNP}$ from $89^{\circ}$ (i.e. nearly perpendicular to the direction of magnetic field) to $1^{0}$ (i.e. nearly parallel to the direction of magnetic field) within 25 minutes, which is the gel time of the present epoxy formulation. Fig. 7a gives the calculated rotation time for the $\mathrm{Fe}_{3} \mathrm{O}_{4} / \mathrm{PVP}-$ GNPs from various initial angles, $\theta_{1}$, to a final angle of $\theta_{2}$ which was taken to be $1.0^{\circ}$ under a magnetic field of $0.009 \mathrm{~T}$. The curve shows a similar trend to that recently reported by Monti et al. [19] on the alignment of one-dimensional carbon nanotubes and our previous work [23] on the alignment of two-dimensional GNPs by an electric field.

From Eq. (5), it can be seen that the rotation time is determined by several variables including the viscosity of the suspension, strength of the magnetic field, diameter and thickness of the $\mathrm{Fe}_{3} \mathrm{O}_{4} / \mathrm{PVP}-\mathrm{GNPs}$ and diameter of the $\mathrm{Fe}_{3} \mathrm{O}_{4}$ nanoparticles. Fig. 7b shows the relationship between the magnetic-field strength and rotation time, indicating that the rotation time significantly decreases upon increasing the magnetic-field strength up to $\sim 0.04 \mathrm{~T}$, above which the time is less dependent on the field strength. In addition, based on Fig. 7c, the time needed to rotate the $\mathrm{Fe}_{3} \mathrm{O}_{4} / \mathrm{PVP}$-GNPs increases linearly as the viscosity of the suspension is increased. Moreover, the magnetic susceptibility, $\chi_{\text {nh }}$, of the $\mathrm{Fe}_{3} \mathrm{O}_{4} /$ PVP-GNPs also plays an important role in the alignment process. This term $\chi_{\mathrm{nh}}$ is determined by the volume fraction, $\varphi$, and the magnetic 
susceptibility, $\chi_{\mathrm{np}}$, of the $\mathrm{Fe}_{3} \mathrm{O}_{4}$ nanoparticles, i.e. $\chi_{\mathrm{nh}}=\chi_{\mathrm{np}} \varphi$, with $\varphi \approx 35 \%$ and $\chi_{\mathrm{np}} \approx 1.98$ [39]. The role of the magnetic susceptibility is presented in Fig. $\mathbf{7 d}$ where the volume fraction of $\mathrm{Fe}_{3} \mathrm{O}_{4}$ in the $\mathrm{Fe}_{3} \mathrm{O}_{4} / \mathrm{PVP}-\mathrm{GNPs}$ is varied. Upon increasing the volume fraction of $\mathrm{Fe}_{3} \mathrm{O}_{4}$ nanoparticles the time required for rotation of the $\mathrm{Fe}_{3} \mathrm{O}_{4} / \mathrm{PVP}-\mathrm{GNPs}$ decreases dramatically. To evaluate the effects of dimensions of the GNPs and $\mathrm{Fe}_{3} \mathrm{O}_{4}$ nanoparticles, the term ' $A$ ' in Eq. (5) can be simplified to give:

$A=\frac{\pi \mu_{0} \chi_{n h}^{2} H^{2}}{16 \eta\left(\chi_{n h}+1\right)} \frac{d}{a}$

because $d \ll a$ and $b \ll a$. Therefore, it is evident that it takes longer to rotate larger nanoplatelets (i.e. which have a greater value of $a$ ) coated with smaller magnetite nanoparticles (i.e. which have a smaller value of $d$ ) under the same conditions. However, the thickness, $b$, of the GNPs does not significantly affect the rotation time. To estimate the longest time required for rotation, the maximum values of the lateral size and thickness based on the supplier's data were used for the calculations. The rotation time would be much shorter (i.e. approximately one-fifth of the values given in Fig. 7a) if the average lateral size and thickness (estimated to be $\sim 5 \mu \mathrm{m}$ and $10 \mathrm{~nm}$, as discussed in Section 3.3) were used for the calculations. 

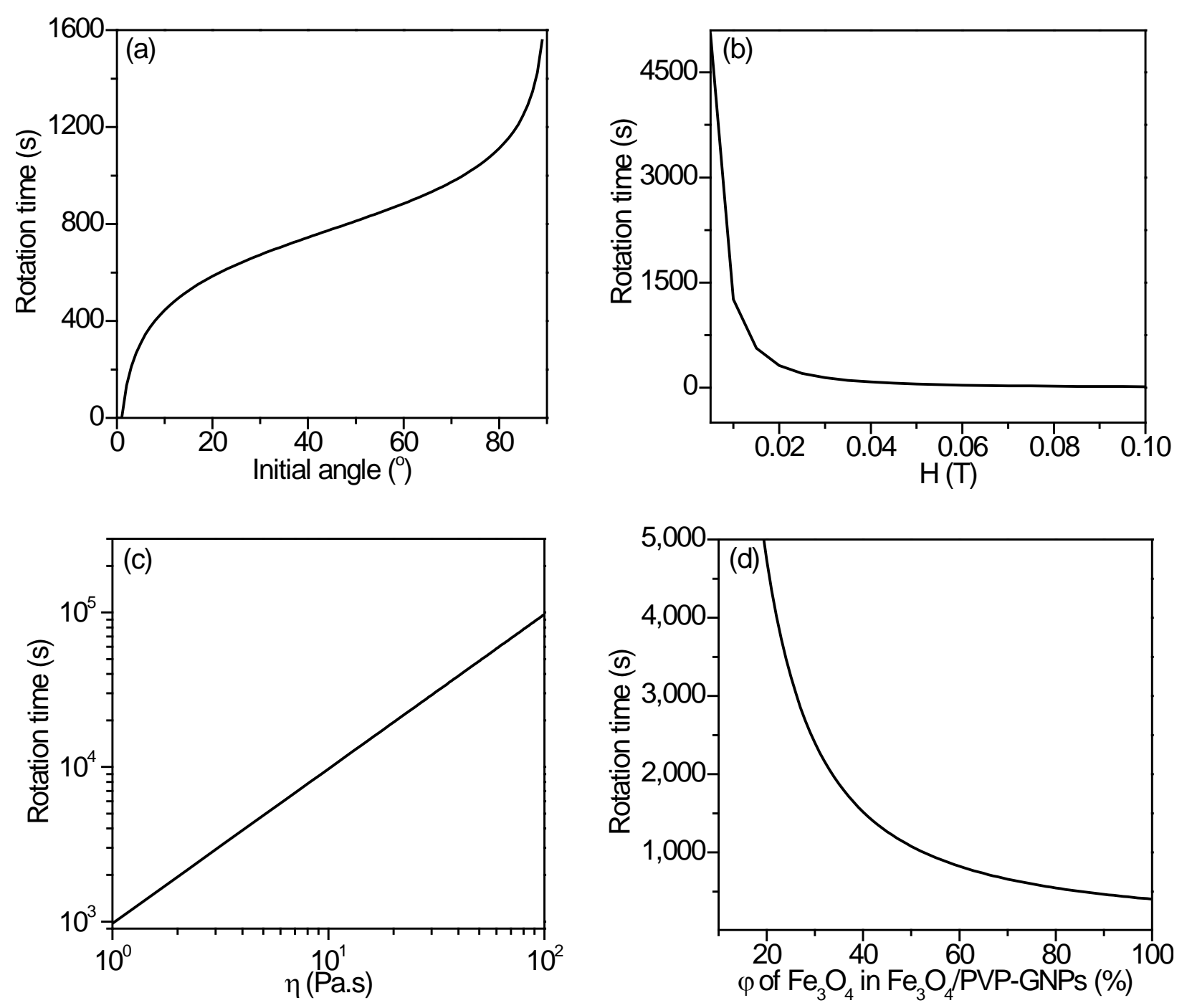

Fig. 7. Plots of the rotation time as a function of the (a) initial angle for the $\mathrm{Fe}_{3} \mathrm{O}_{4} / \mathrm{PVP}-\mathrm{GNPs}$ nanohybrids; (b) magnetic-field strength; (c) viscosity of the suspension; and (d) volume fraction of $\mathrm{Fe}_{3} \mathrm{O}_{4}$ in the $\mathrm{Fe}_{3} \mathrm{O}_{4} / \mathrm{PVP}-\mathrm{GNPs}$. (Note that the initial angle $\left(\theta_{1}\right)$ was set to be $89^{\circ}$ for (b), (c), and (d) and a magnetic-field strength of 0.009 T was used in the calculations for (a), (c), and (d).)

\subsubsection{Experimental studies}

The magnetic-field strength employed in the present work was selected based on the theoretical modelling results discussed above, such that the alignment of $\mathrm{Fe}_{3} \mathrm{O}_{4} / \mathrm{PVP}-\mathrm{GNPs}$ nanohybrids would be completed prior to gelation of the epoxy resin. The gelation time of the epoxy is about 
25 to 30 minutes at $25{ }^{\circ} \mathrm{C}$. In practical experiments, it took up to $\sim 15$ minutes to mix thoroughly the epoxy resin with the hardener and to degas the mixture before the magnetic field could then be applied. Therefore, there is only 10 minutes time available for the alignment process. During this time, the viscosity of the epoxy resin was increased from its initial value of $1.6 \mathrm{~Pa} \cdot \mathrm{s}$ to 2.7 Pa's according to the viscosity-time curve (Fig. S1) of the 'epoxy + hardener' system. (The viscosity-time curve was obtained from an isothermal test carried out at $25{ }^{\circ} \mathrm{C}$ immediately after the mixing of epoxy with hardener.) Based on Eq. (5), a magnetic field of $0.02 \mathrm{~T}$ would be required to rotate a $\mathrm{Fe}_{3} \mathrm{O}_{4} / \mathrm{PVP}-\mathrm{GNP}$ from $89^{\circ}$ to $1^{\circ}$ in approximately $531 \mathrm{~s}$ ( $\sim 9$ minutes) in epoxy reactive system with viscosity of $2.7 \mathrm{~Pa} \cdot \mathrm{s}$. Therefore, a magnetic field of $0.02 \mathrm{~T}$ was selected and applied to align the $\mathrm{Fe}_{3} \mathrm{O}_{4} /$ PVP-GNPs.

The alignment of the $\mathrm{Fe}_{3} \mathrm{O}_{4} / \mathrm{PVP}-\mathrm{GNPs}$ nanohybrids in the epoxy polymer was experimentally investigated using SEM and TEM. For the epoxy/ $/ \mathrm{Fe}_{3} \mathrm{O}_{4} / \mathrm{PVP}-\mathrm{GNPs}$ nanocomposites prepared without applying the external magnetic field, no indication of any alignment was found, as shown in Figs. 8a and c. By contrast, for the nanocomposites subjected to the magnetic field of $\sim 0.02 \mathrm{~T}$, it is expected that the $\mathrm{Fe}_{3} \mathrm{O}_{4} / \mathrm{PVP}$-GNPs would be aligned along the direction of the magnetic field based on the above theoretical calculations. This is confirmed by the SEM and TEM images shown in Figs. 8b and 8d. 

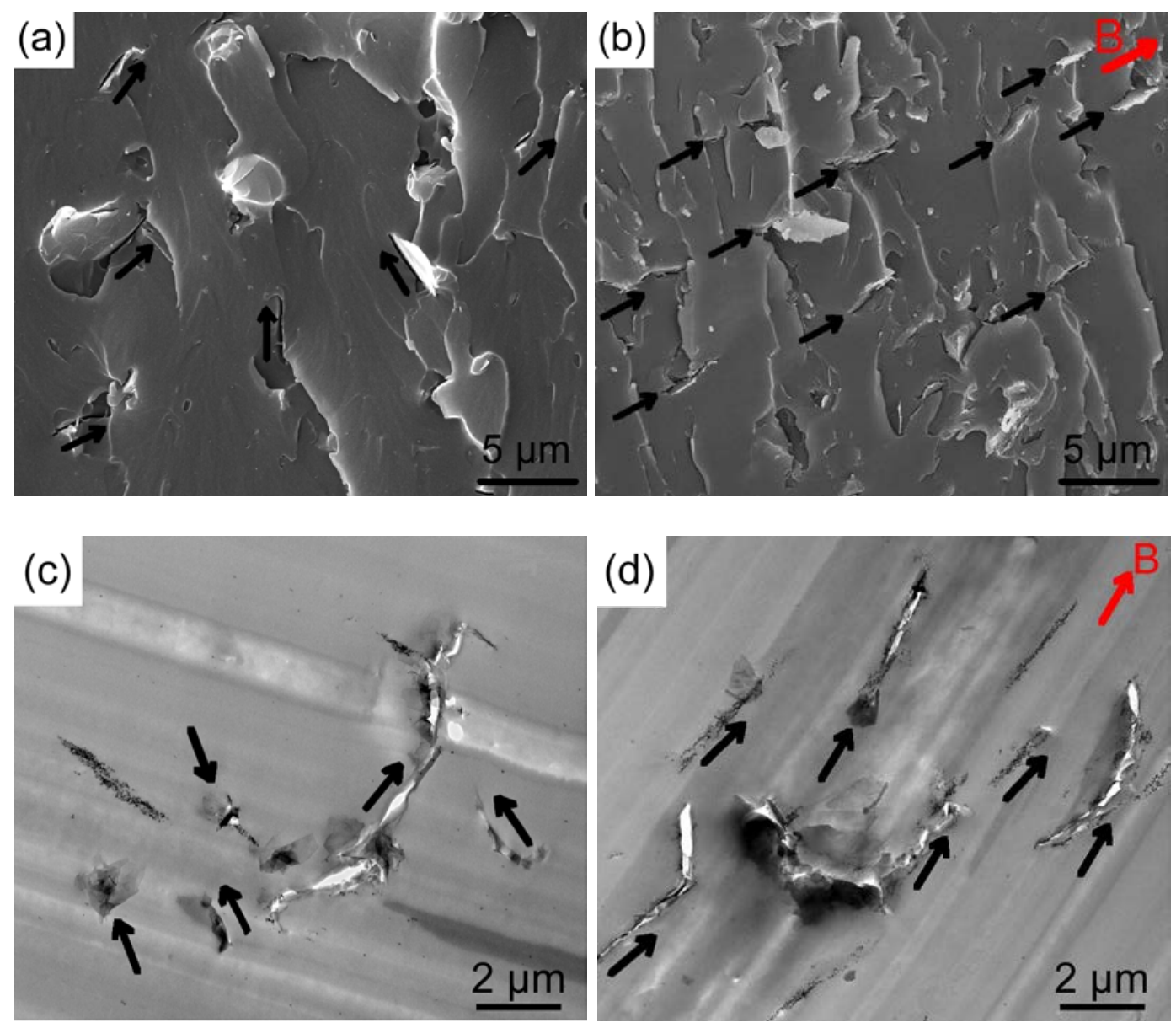

Fig. 8. SEM images of epoxy polymer nanocomposites with 1 wt $\%$ of (a) randomly-oriented $\mathrm{Fe}_{3} \mathrm{O}_{4} /$ PVP-GNPs and (b) aligned $\mathrm{Fe}_{3} \mathrm{O}_{4} /$ PVP-GNPs; TEM images of epoxy polymer nanocomposites with (c) randomly-oriented $\mathrm{Fe}_{3} \mathrm{O}_{4} /$ PVP-GNPs and (d) aligned $\mathrm{Fe}_{3} \mathrm{O}_{4} /$ PVP-GNPs. The direction of the external magnetic field is indicated by red arrow while the black arrows indicate the orientation of the GNPs.

\subsection{Toughness of the epoxy polymer nanocomposites}

The mode I fracture behaviour of the carbon-fibre composite joints bonded by the epoxy polymer nanocomposites (or the unmodified epoxy) was studied to investigate the effects of the alignment of the $\mathrm{Fe}_{3} \mathrm{O}_{4} / \mathrm{PVP}-\mathrm{GNPs}$ nanohybrids on the fracture energy and toughening mechanisms. 'Saw- 
tooth' shaped load versus displacement curves were obtained for the unmodified epoxy and all the epoxy nanocomposites, demonstrating unstable, 'stick-slip' crack growth behaviour, similar to the epoxy/CNFs and epoxy/GNPs nanocomposites studied in our previous work [22, 23, 25]. Fig. 9a shows the typical load versus displacement curves for the epoxy polymer nanocomposites containing 1 wt $\%$ of randomly-oriented and aligned $\mathrm{Fe}_{3} \mathrm{O}_{4} /$ PVP-GNPs. The unmodified epoxy exhibits an average fracture energy, $\mathrm{G}_{\mathrm{Ic}}$, of $134 \pm 16.2 \mathrm{~J} / \mathrm{m}^{2}$, which increases to $375 \pm 19.6$ and $546 \pm 20.4 \mathrm{~J} / \mathrm{m}^{2}$ with the addition of $0.5 \mathrm{wt} \%$ and $1 \mathrm{wt} \%$ of randomly-oriented $\mathrm{Fe}_{3} \mathrm{O}_{4} / \mathrm{PVP}-\mathrm{GNPs}$, respectively (Fig. 9b). Application of the magnetic field, in the direction normal to the subsequent crack growth, significantly improved the fracture energy. Compared to the nanocomposites with randomly-oriented $\mathrm{Fe}_{3} \mathrm{O}_{4} / \mathrm{PVP}-\mathrm{GNPs}$, the values of $\mathrm{G}_{\text {Ic }}$ were further increased by $\sim 20 \%$ and $\sim 50 \%$ for the epoxy nanocomposites with $0.5 \mathrm{wt} \%$ and $1 \mathrm{wt} \%$ of aligned $\mathrm{Fe}_{3} \mathrm{O}_{4} / \mathrm{PVP}-\mathrm{GNPs}$, respectively. However, it is noteworthy, that, when the $\mathrm{Fe}_{3} \mathrm{O}_{4} / \mathrm{PVP}-$ GNPs were aligned parallel to the crack growth direction, the value of $G_{\text {Ic }}$ only slightly decreased by $\sim 15 \%$ compared to those nanocomposites containing the randomly-oriented nanofillers.

The improvements in the fracture energy achieved by the addition of the $\mathrm{Fe}_{3} \mathrm{O}_{4} / \mathrm{PVP}-\mathrm{GNPs}$ in the present work have been compared with reported values for epoxy-based nanocomposites containing different types of GNPs. Table 1. gives the maximum percentage increases in the values of the fracture energy, $\mathrm{G}_{\mathrm{Ic}}$, (or the fracture toughness, $\mathrm{K}_{\mathrm{Ic}}$ ) and the corresponding nanofiller content. As may be seen, the incorporation of GNPs does always tend to increase significantly the value of $\mathrm{G}_{\mathrm{Ic}}$ (or $\mathrm{K}_{\mathrm{Ic}}$ ) of the epoxy polymer at low loadings (mostly lower than, or equal to, about $1 \mathrm{wt} \%)$. Notwithstanding, the improvements achieved in the present studies by 
the addition of the $\mathrm{Fe}_{3} \mathrm{O}_{4}$ /PVP-GNPs (both randomly-dispersed and aligned) are impressive, especially when the aligned $\mathrm{Fe}_{3} \mathrm{O}_{4}$ /PVP-GNPs are employed. However, it is noteworthy that the fracture energies of these epoxy polymer nanocomposites are not as high as those of the epoxy/GNPs nanocomposites prepared in our previous work [23], i.e. when a maximum improvement of $\sim 900 \%$ was observed. This observation is very likely to be due to the smaller size of the present functionalized $\mathrm{Fe}_{3} \mathrm{O}_{4}$ /PVP-GNPs compared with the pristine GNPs (i.e. without any functionalization) that were used previously [23, 41]. This suggestion is supported via using a mechanistic fracture model which has been successfully employed to predict the improvements in the value of $\mathrm{G}_{\mathrm{Ic}}$ of polymer nanocomposites which incorporated twodimensional pristine GNPs [42]. This model has now, therefore, been used to estimate $\mathrm{G}_{\text {Ic }}$ for the randomly-orientated nanocomposites studied in the present work. For the present functionalised $\mathrm{Fe}_{3} \mathrm{O}_{4} / \mathrm{PVP}-\mathrm{GNPs}$, the thickness and lateral dimensions used for the calculations were $10 \mathrm{~nm}$ (i.e. half the thickness of pristine GNPs) and $5 \mu \mathrm{m}$ (i.e. one fifth of the lateral size of pristine GNPs), respectively. The lateral size of the $\mathrm{Fe}_{3} \mathrm{O}_{4}$ /PVP-GNPs was estimated based on the images shown in Fig. 8. The thickness of the $\mathrm{Fe}_{3} \mathrm{O}_{4} / \mathrm{PVP}-\mathrm{GNPs}$ was decreased due to the presence of the PVP stabilizer, which facilitates the exfoliation of the GNPs. However, it is difficult to measure accurately the thickness of hybrid nanofillers and it was therefore assumed to be half that of the thickness of the pristine GNPs. The modelling results are shown in Fig. $\mathbf{9 b}$ and the theoretical calculations of $\mathrm{G}_{\mathrm{Ic}}$ for the randomly-oriented $\mathrm{Fe}_{3} \mathrm{O}_{4}$ /PVP-GNPs epoxy nanocomposites are in very good agreement with the experimental results. This strongly supports the suggestion that the values of $\mathrm{G}_{\text {Ic }}$ of the present epoxy polymer nanocomposites are not as high as those of the epoxy/(pristine) GNPs nanocomposites prepared in our previous work [23] due to the smaller 
size of the functionalized $\mathrm{Fe}_{3} \mathrm{O}_{4} / \mathrm{PVP}-\mathrm{GNPs}$ compared with the pristine GNPs (i.e. without any functionalization) that were used previously [23, 41].
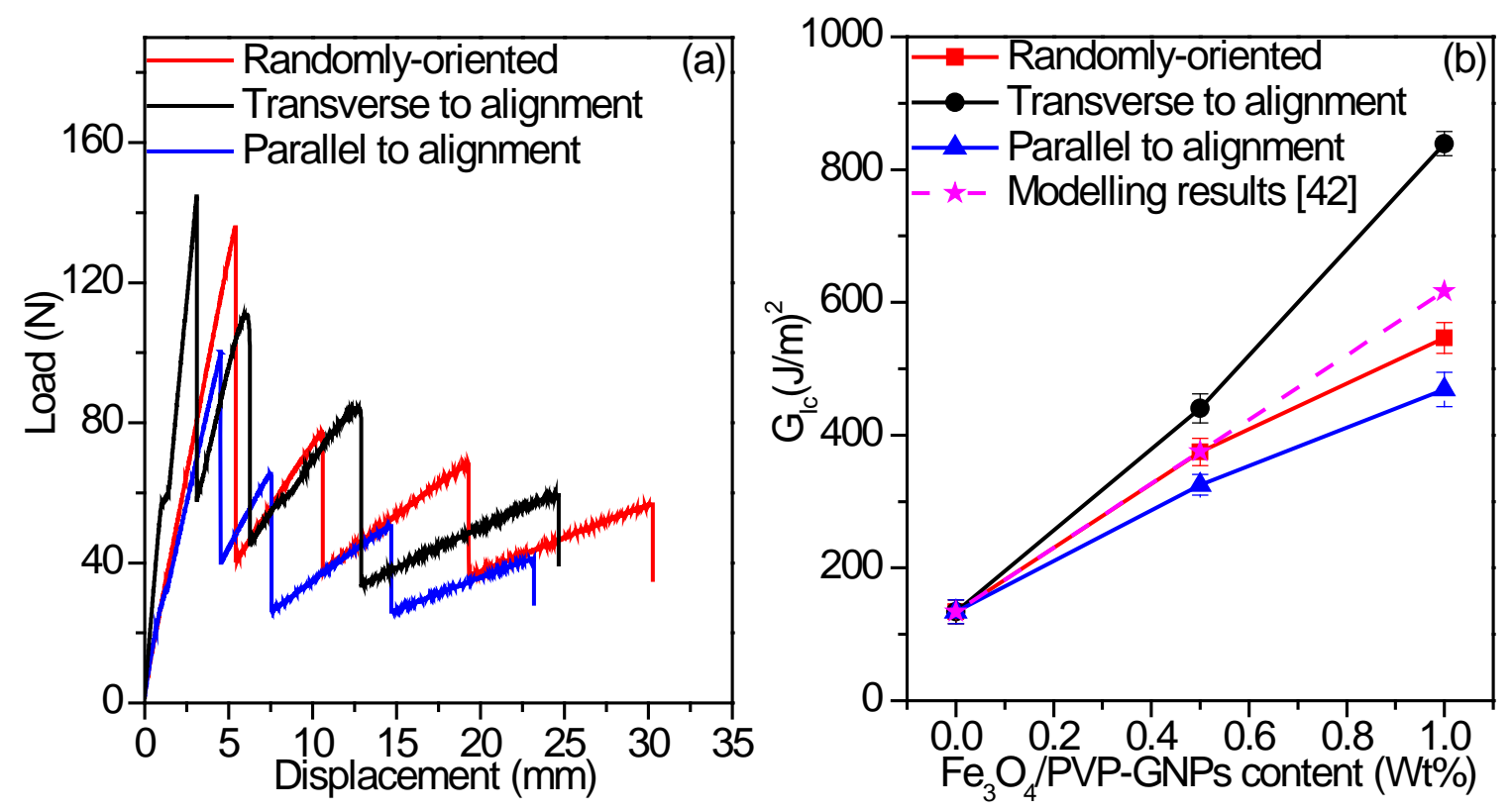

Fig. 9. (a) Representative load versus displacement curves of the epoxy nanocomposites with 1.0 wt $\%$ of randomly-oriented or aligned $\mathrm{Fe}_{3} \mathrm{O}_{4} /$ PVP-GNPs; (b) mode I fracture energy, $\mathrm{G}_{\text {Ic }}$, of the epoxy nanocomposites as a function of the $\mathrm{Fe}_{3} \mathrm{O}_{4} / \mathrm{PVP}$-GNPs content. (The alignment direction of the $\mathrm{Fe}_{3} \mathrm{O}_{4} / \mathrm{PVP}-\mathrm{GNPs}$ with respect to the crack growth direction is indicated.) 
Table 1. Summary of maximum percentage increase (compared to the unmodified epoxy) in $\mathrm{G}_{\text {IC }}$ or $\mathrm{K}_{\mathrm{Ic}}$ of epoxy/graphene nanocomposites from the present studies and previously reported in the literature.

\begin{tabular}{|c|c|c|c|c|c|}
\hline \multicolumn{2}{|l|}{ Filler } & Fracture test $^{\mathrm{a}}$ & $\begin{array}{l}\text { Maximum } \\
\text { increase in } G_{I c} b\end{array}$ & $\begin{array}{l}\text { Maximum } \\
\text { increase in } \mathrm{K}_{\mathrm{Ic}}{ }^{\mathrm{c}}\end{array}$ & Ref. \\
\hline \multirow{2}{*}{$\begin{array}{l}\mathrm{Fe}_{3} \mathrm{O}_{4} / \mathrm{PVP} \\
\text {-GNPs }\end{array}$} & $\begin{array}{l}\text { Randomly- } \\
\text { oriented }\end{array}$ & \multirow{2}{*}{ DCB } & $307 \%$ (1 wt\%) & & \multirow{2}{*}{$\begin{array}{l}\text { The present } \\
\text { work }\end{array}$} \\
\hline & Aligned & & $530 \%$ (1 wt\%) & & \\
\hline \multirow{2}{*}{ GNPs } & $\begin{array}{l}\text { Randomly- } \\
\text { oriented }\end{array}$ & \multirow{2}{*}{ DCB } & $684 \%$ (2 wt\%) & & \multirow{2}{*}[23]{} \\
\hline & Aligned & & 891 \% (1.5 wt\%) & & \\
\hline \multicolumn{2}{|c|}{ Graphene foam } & SENB & & $70 \%$ (0.1 wt\%) & {$[43]$} \\
\hline \multicolumn{2}{|l|}{ GO } & SENB & & $75 \%(0.1 \mathrm{wt} \%)$ & {$[44]$} \\
\hline \multicolumn{2}{|c|}{ Graphite nanoplatelets } & \multirow{2}{*}{ SENB } & & $50 \%(1.0 \mathrm{wt} \%)$ & {$[45]$} \\
\hline \multicolumn{2}{|c|}{ Thermally reduced GO } & & & $40 \%(0.5 \mathrm{wt} \%)$ & {$[46]$} \\
\hline \multicolumn{2}{|l|}{ GO } & SENB & $111 \%(1 \mathrm{wt} \%)$ & & {$[47]$} \\
\hline \multicolumn{2}{|c|}{$\begin{array}{l}\text { 4,4'-methylene diphenyl } \\
\text { diisocyanate modified } \\
\text { graphene }\end{array}$} & CT & $200 \%(4 \mathrm{wt} \%)$ & & [48] \\
\hline \multicolumn{2}{|c|}{$\begin{array}{l}\text { 4,4'- } \\
\text { diaminophenylsulfone } \\
\text { modified graphene }\end{array}$} & CT & $196 \%$ (1 wt\%) & & [49] \\
\hline \multicolumn{2}{|c|}{$\begin{array}{l}\text { Poly(butadiene } \\
\text { acrylonitrile) modified } \\
\text { graphene oxide (GO) }\end{array}$} & CT & $140 \%$ (0.04 wt\%) & & {$[50]$} \\
\hline \multicolumn{2}{|c|}{ Thermally expanded GO } & CT & $115 \%$ (0.125 wt\%) & & {$[51]$} \\
\hline
\end{tabular}

${ }^{a}$ Fracture tests: DCB (double cantilever beam) test; CT (compact tension); SENB (single-edge notch bending).

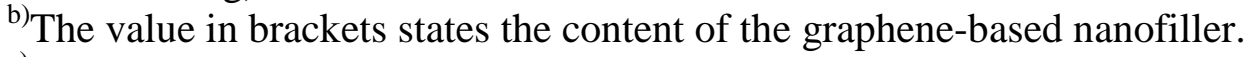

${ }^{c} \mathrm{~K}_{\mathrm{Ic}}$ is the critical value of the stress-intensity factor for fracture. 
The fracture surfaces were examined to identify the toughening mechanisms. Distinct "thumbnail lines” were observed on the fracture surface as shown in Fig. 10a. These are the regions where cracks initiated and then arrested. Stress-whitening of the epoxy was observed along these lines. Figs. 10b-d show the SEM images of these regions. For the unmodified epoxy, a relatively featureless and smooth fracture surface was observed (Fig. 10b), which is typical for brittle materials with low values of fracture toughness. Figs. 10 c-d show the SEM images of the epoxy polymer nanocomposites containing different concentrations of the $\mathrm{Fe}_{3} \mathrm{O}_{4} / \mathrm{PVP}-\mathrm{GNPs}$ nanohybrids, on which patterns of tear marks were observed. These much rougher surfaces are likely due to crack deflection induced by the presence of the $\mathrm{Fe}_{3} \mathrm{O}_{4} / \mathrm{PVP}-\mathrm{GNPs}$. The toughening mechanisms for the epoxy nanocomposites containing multilayered GNPs were investigated in our previous study [23], which revealed that intrinsic toughening processes, i.e. interfacial debonding and void growth, are important toughening mechanisms. These toughening processes were also observed for the present epoxy polymer nanocomposites. Discrete microcracks could be seen on the fracture surfaces, as indicated by the arrows in Figs. 10c-d. SEM images shown in Figs. 11a-b are from the fracture surface at higher magnifications, revealing a microcrack that was created due to interfacial debonding at the epoxy-GNP interfaces and delamination between the GNPs. In addition, evidence revealing the fracture and pull-out of the $\mathrm{Fe}_{3} \mathrm{O}_{4} / \mathrm{PVP}$-GNPs was also found, as shown in Fig. 11. Crack bridging by the pulled-out $\mathrm{Fe}_{3} \mathrm{O}_{4} / \mathrm{PVP}-\mathrm{GNPs}$ is revealed in Fig. 11c, which is an SEM image of the crack tip region (side-view) of a DCB specimen.

The alignment of the $\mathrm{Fe}_{3} \mathrm{O}_{4} / \mathrm{PVP}-\mathrm{GNPs}$ nanohybrids in the direction transverse to crack growth direction increases the likelihood of the main crack encountering them. Interactions between the crack and the aligned $\mathrm{Fe}_{3} \mathrm{O}_{4} / \mathrm{PVP}$-GNPs induce more crack deflection and/or branching. 
Moreover, the extrinsic toughening processes (i.e. pull-out and fracture of the $\mathrm{Fe}_{3} \mathrm{O}_{4} / \mathrm{PVP}-\mathrm{GNPs}$ and crack bridging by the $\mathrm{Fe}_{3} \mathrm{O}_{4} / \mathrm{PVP}-\mathrm{GNPs}$ ) are more significant when the $\mathrm{Fe}_{3} \mathrm{O}_{4} / \mathrm{PVP}-\mathrm{GNPs}$ are aligned transverse to the crack growth direction. Thus, relatively higher values of fracture energy are obtained for the nanocomposites containing $\mathrm{Fe}_{3} \mathrm{O}_{4} / \mathrm{PVP}$-GNPs aligned transversely to the crack growth direction.
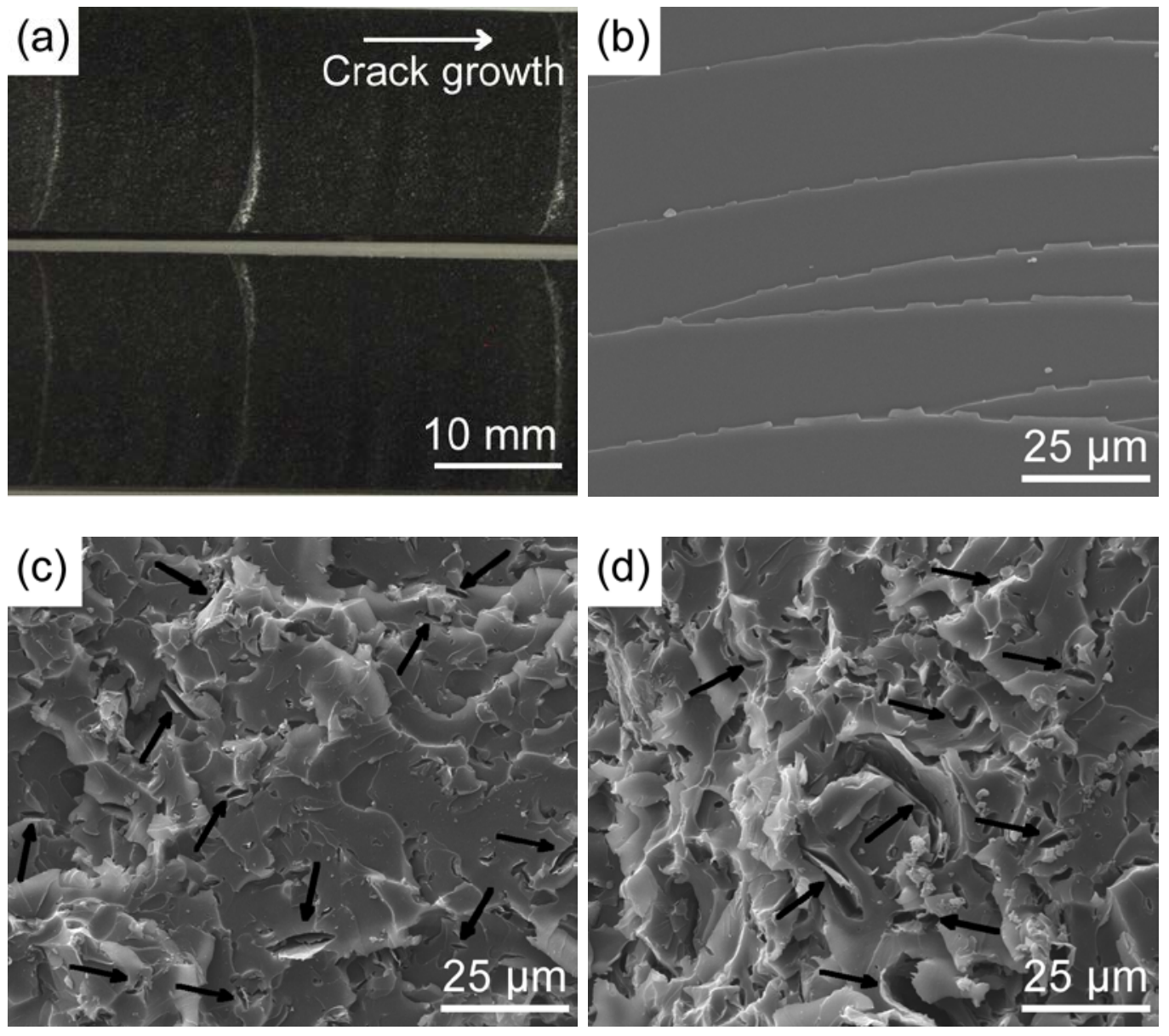

Fig. 10. (a) A typical photograph of the crack fronts on the fracture surface of a DCB specimen bonded with an epoxy polymer nanocomposite containing 1 wt $\%$ of aligned $\mathrm{Fe}_{3} \mathrm{O}_{4} / \mathrm{PVP}-\mathrm{GNPs}$; SEM images of the fracture surfaces of (b) the unmodified epoxy polymer and (c-d) the epoxy 
polymer nanocomposites containing 0.5 wt $\%$ and 1.0 wt $\%$ of $\mathrm{Fe}_{3} \mathrm{O}_{4} / \mathrm{PVP}-\mathrm{GNPs}$ aligned transversely to crack growth, respectively.

(a)
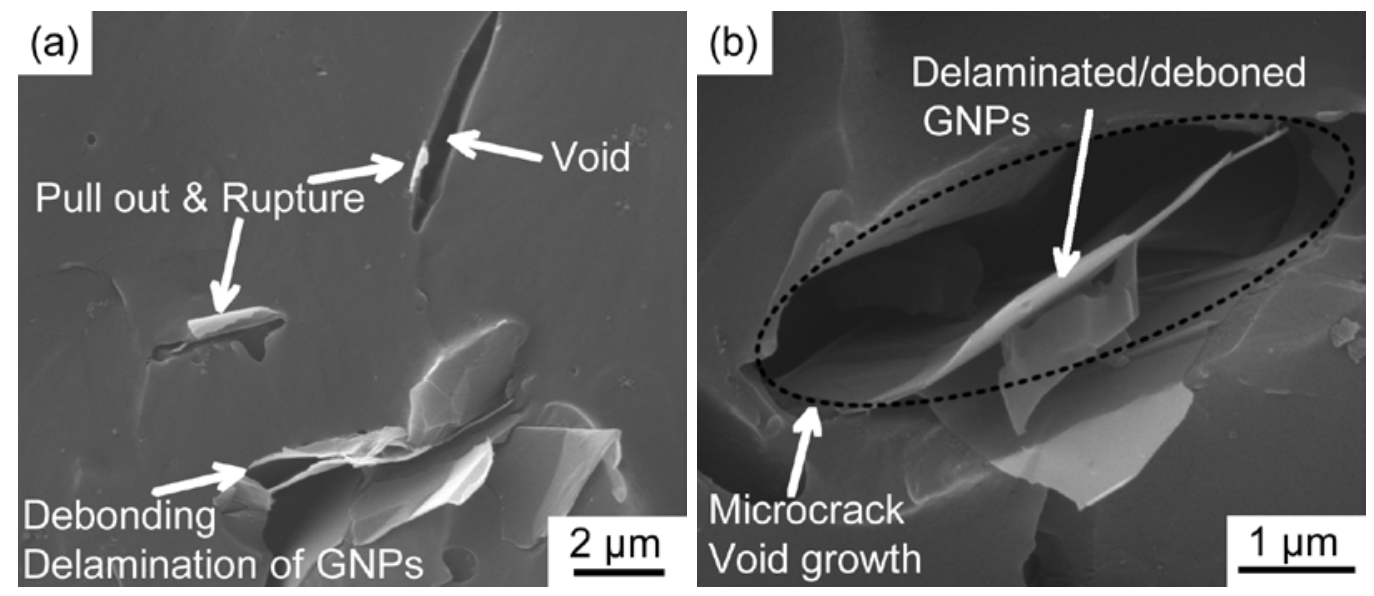

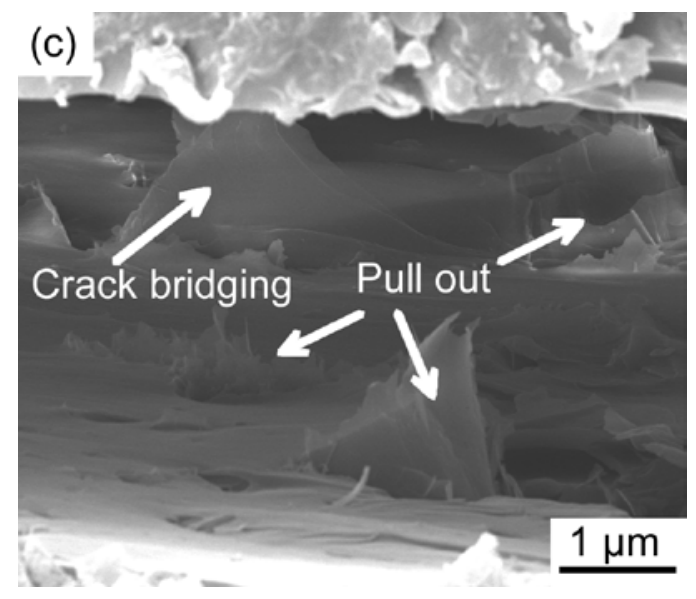

Fig. 11. (a) and (b) SEM micrographs from the fracture surfaces of a DCB specimen for an epoxy polymer nanocomposite containing $1 \mathrm{wt} \%$ aligned $\mathrm{Fe}_{3} \mathrm{O}_{4} / \mathrm{PVP}-\mathrm{GNPs}$, revealing evidence of pull-out and rupture of the $\mathrm{Fe}_{3} \mathrm{O}_{4} / \mathrm{PVP}-\mathrm{GNPs}$, debonding at the epoxy-GNP interfaces and delamination of the $\mathrm{Fe}_{3} \mathrm{O}_{4} / \mathrm{PVP}$-GNPs; (c) SEM image of the crack tip region (side-view) of a DCB specimen revealing crack bridging and pull-out of the $\mathrm{Fe}_{3} \mathrm{O}_{4} /$ PVP-GNPs.

\subsection{Electrical conductivity of the epoxy polymer nanocomposites}


Fig. 12 shows the electrical conductivity of the unmodified epoxy polymer and the epoxy polymer nanocomposites layer in the bonded DCB joints, measured in the through-thickness direction of the bonded specimen. The results demonstrate that the electrical conductivity of the epoxy nanocomposite is increased by approximately two and three orders of magnitude when they contain $0.5 \mathrm{wt} \%$ and $1.0 \mathrm{wt} \%$ of $\mathrm{Fe}_{3} \mathrm{O}_{4} / \mathrm{PVP}-\mathrm{GNPs}$ nanohybrids, respectively. It is also found that the conductivity of the nanocomposites is consistently higher in the alignment direction than that of the samples containing randomly-oriented $\mathrm{Fe}_{3} \mathrm{O}_{4} / \mathrm{PVP}$-GNPs. This proves that the aligned $\mathrm{Fe}_{3} \mathrm{O}_{4} / \mathrm{PVP}$-GNPs contribute more effectively to increase the electrical conductivity. However, the electrical conductivity is slightly lower if $\mathrm{Fe}_{3} \mathrm{O}_{4} / \mathrm{PVP}-\mathrm{GNPs}$ are aligned perpendicular to the measurement direction (the magnetic field was applied in the inplane direction). This directional dependence of the electric conductivity is attributed to the higher electrical conductivity of the GNPs parallel to their surface than through their thickness [23]. The addition of conductive nanofillers into insulating polymers induces electrical conduction due to the formation of conductive pathways [52]. However, without reaching a critical content, a three-dimensional conductive network is formed and the conductivity is dominantly due to a tunnelling conduction mechanism [53].

It is noteworthy that the electrical conductivity of the epoxy nanocomposites containing $\mathrm{Fe}_{3} \mathrm{O}_{4} / \mathrm{PVP}-\mathrm{GNPs}$ is lower than that of similar epoxy polymer nanocomposites containing pristine GNPs, as reported in our previous work [23]. This may be due to the treatment of the GNPs with PVP which is adsorbed onto the basal plane of the GNPs, forming an insulting layer. The coating of GNPs by insulating $\mathrm{Fe}_{3} \mathrm{O}_{4}$ nanoparticles hinders the tunnelling of electrons between particles [54]. Moreover, due to the treatment using the ultrasonic homogenizer, the 
GNPs were broken into platelets of smaller sizes, resulting in a lower electrical conductivity when they are used as nanofillers for polymers [55].

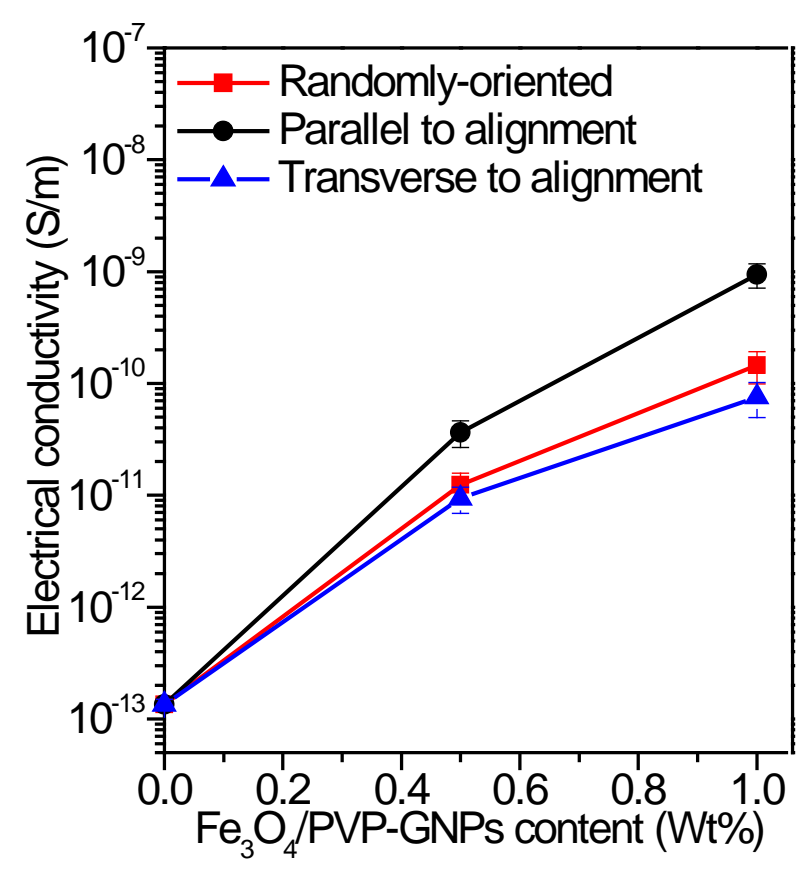

Fig. 12. Electrical conductivity of the epoxy polymer nanocomposites as a function of the concentration of $\mathrm{Fe}_{3} \mathrm{O}_{4} / \mathrm{PVP}-\mathrm{GNPs}$ nanohybrids. (Note: The conductivity was measured in the through-thickness direction of the DCB composite joints. The alignment direction of the nanohybrids with respect to the measurement direction is indicated)

\section{Conclusions}

In the present work, superparamagnetic $\mathrm{Fe}_{3} \mathrm{O}_{4} / \mathrm{PVP}-\mathrm{GNPs}$ nanohybrids have been successfully fabricated by non-covalently attaching $\mathrm{Fe}_{3} \mathrm{O}_{4}$ nanoparticles onto PVP-GNPs. The as-received multi-layered GNPs were used as the starting materials, which can be dispersed in water and form stable aqueous dispersions with the addition of $\mathrm{PVP} . \mathrm{Fe}_{3} \mathrm{O}_{4}$ nanoparticles were then coprecipitated onto the PVP-GNPs, forming magnetic $\mathrm{Fe}_{3} \mathrm{O}_{4} / \mathrm{PVP}-\mathrm{GNPs}$ nanohybrids. The 
$\mathrm{Fe}_{3} \mathrm{O}_{4} / \mathrm{PVP}-\mathrm{GNPs}$ nanohybrids can be readily aligned in an epoxy resin by applying a relatively weak magnetic field which has been verified both experimentally and theoretically. The theoretical model identifies the key parameters influencing the alignment process, including the viscosity of the suspension, the strength of the magnetic field, the dimension (i.e. diameter and thickness) of the nanoplatelets, the diameter of the magnetite nanoparticles, and the magnetic susceptibility of the nanohybrids.

The addition of the $\mathrm{Fe}_{3} \mathrm{O}_{4}$ /PVP-GNPs nanohybrids to the epoxy polymer has led to a major increase in the fracture energy and electrical conductivity, compared with the unmodified epoxy polymer. Furthermore, alignment of the $\mathrm{Fe}_{3} \mathrm{O}_{4} / \mathrm{PVP}$-GNPs nanohybrids significantly improves the toughening efficiency and the electrical conductivity. More specifically, compared with the epoxy polymer nanocomposites containing randomly-oriented $\mathrm{Fe}_{3} \mathrm{O}_{4} / \mathrm{PVP}-\mathrm{GNPs}$, up to about a $50 \%$ enhancement in fracture energy has been achieved when the nanohybrids are aligned transverse to the subsequent crack growth direction and a seven-fold increase in electrical conductivity measured in the alignment direction. Fractographic studies revealed that the primary toughening mechanisms of the nanohybrids include interfacial debonding, epoxy void growth, pull-out and rupture of the $\mathrm{Fe}_{3} \mathrm{O}_{4} /$ PVP-GNPs, and crack bridging by the $\mathrm{Fe}_{3} \mathrm{O}_{4} /$ PVP-GNPs.

\section{Acknowledgements}

The authors are thankful for the financial support received from the Australian Research Council's Discovery Grant (DP140100778). The authors also want to acknowledge Dr. Muthu Pannirselvam from the Rheology and Materials Characterization Laboratory at RMIT University for assisting with the rheological measurement. 


\section{Appendix A. Supplementary data}

Supplementary data associated with this article can be found in the online version, at...........

\section{References}

[1] J. R. Potts, D. R. Dreyer, C. W. Bielawski, R. S. Ruoff, Polymer, 2011, 52, 5-25.

[2] X. Zhang, O. Alloul, Q. L. He, J. H. Zhu, M. J. Verde, Y. T. Li, S. Y. Wei, Z. H. Guo, Polymer, 2013, 54, 3594-3604.

[3] M. Yoonessi, D. A. Scheiman, M. Dittler, J. A. Peck, J. Ilavsky, J. R. Gaier, M. A. Meador, Polymer, 2013, 54, 2776-2784.

[4] A. Pourjavadi, Z. M. Tehrani, S. Jokar, Polymer, 2015, 76, 52-61.

[5] J. Hu, Y. L. Dong, X. J. Chen, H. J. Zhang, J. M. Zheng, Q. Wang, X. G. Chen, Chem. Eng. J., 2014, 236, 1-8.

[6] Y. C. Dong, K. C. Yung, R. G. Ma, X. Yang, Y. S. Chui, J. M. Lee, J. A. Zapien, Carbon, 2015, 86, 310-317.

[7] L. L. Zhang, X. X. Yu, H. R. Hu, Y. Li, M. Z. Wu, Z. Z. Wang, G. Li, Z. Q. Sun, C. L. Chen, Sci. Rep., 2015, 5, 9.

[8] W. C. Jiao, M. Shioya, R. G. Wang, F. Yang, L. F. Hao, Y. Niu, W. B. Liu, L. Zheng, F. Yuan, L. Wan, X. D. He, Compos. Sci. Technol., 2014, 99, 124-130.

[9] H. Y. Yan, Y. X. Tang, W. Long, Y. F. Li, J. Mater. Sci., 2014, 49, 5256-5264.

[10] P. N. Diagboya, B. I. Olu-Owolabi, K. O. Adebowale, RSC Adv., 2015, 5, 2536-2542.

[11] H. K. He, C. Gao, ACS Appl. Mater. Interfaces, 2010, 2, 3201-3210.

[12] W. Baaziz, L. Truong-Phuoc, C. Duong-Viet, G. Melinte, I. Janowska, V. Papaefthimiou, O. Ersen, S. Zafeiratos, D. Begin, S. Begin-Colin, C. Pham-Huu, J. Mater. Chem. A, 2014, 2, 2690-2700.

[13] R. J. Fullerton, D. P. Cole, K. D. Behler, S. Das, F. Irin, D. Parviz, M. N. F. Hoque, Z. Fan, M. J. Green, Carbon, 2014, 72, 192-199.

[14]D. G. Papageorgiou, I. A. Kinloch, R. J. Young, Carbon, 2015, 95, 460-484.

[15]Z. Li, R. Wang, R. J. Young, L. Deng, F. Yang, L. Hao, W. Jiao, W. Liu, Polymer, 2013, 54, 6437-6446. 
[16] A. M. Marconnet, N. Yamamoto, M. A. Panzer, B. L. Wardle, K. E. Goodson, ACS Nano, 2011, 5, 4818-4825.

[17]E. J. Garcia, B. L. Wardle, A. John Hart, N. Yamamoto, Compos. Sci. Technol., 2008, 68, 2034-2041.

[18] N. Yamamoto, R. Guzman de Villoria, B. L. Wardle, Compos. Sci. Technol., 2012, 72, 2009-2015.

[19] M. Monti, M. Natali, L. Torre, J. M. Kenny, Carbon, 2012, 50, 2453-2464.

[20] C. Ma, W. Zhang, Y. F. Zhu, L. J. Ji, R. P. Zhang, N. Koratkar, J. Liang, Carbon, 2008, 46, 706-710.

[21] C. S. Lim, A. J. Rodriguez, M. E. Guzman, J. D. Schaefer, B. Minaie, Carbon, 2011, 49, 1873-1883.

[22] R. B. Ladani, S. Wu, A. J. Kinloch, K. Ghorbani, J. Zhang, A. P. Mouritz, C. H. Wang, Compos. Sci. Technol., 2015, 117, 146-158.

[23] S. Wu, R. B. Ladani, J. Zhang, E. Bafekrpour, K. Ghorbani, A. P. Mouritz, A. J. Kinloch, C. H. Wang, Carbon, 2015, 94, 607-618.

[24]E. Camponeschi, R. Vance, M. Al-Haik, H. Garmestani, R. Tannenbaum, Carbon, 2007, 45, 2037-2046.

[25] S. Wu, R. B. Ladani, J. Zhang, A. J. Kinloch, Z. Zhao, J. Ma, X. Zhang, A. P. Mouritz, K. Ghorbani, C. H. Wang, Polymer, 2015, 68, 25-34.

[26] A. S. Wajid, S. Das, F. Irin, H. S. T. Ahmed, J. L. Shelburne, D. Parviz, R. J. Fullerton, A. F. Jankowski, R. C. Hedden, M. J. Green, Carbon, 2012, 50, 526-534.

[27] J. Zhang, J. F. Wang, T. Lin, C. H. Wang, K. Ghorbani, J. Fang, X. G. Wang, Chem. Eng. J., 2014, 237, 462-468.

[28]B. R. K. BlackmanA. J. Kinloch, Fracture tests on structural adhesive joints, in European Structural Integrity Society, A.P. D.R. Moore and J.G. Williams, Editors. 2001, Elsevier. p. 225-267.

[29] I. T. Kim, G. A. Nunnery, K. Jacob, J. Schwartz, X. T. Liu, R. Tannenbaum, J. Phys. Chem. C, 2010, 114, 6944-6951.

[30] S. Wang, Y. Zhou, W. Guan, B. Ding, Appli. Surf. Sci., 2008, 254, 5170-5174.

[31] J. Zhou, H. Song, L. Ma, X. Chen, RSC Adv., 2011, 1, 782-791. 
[32] Y. Cheng, B. Zou, C. Wang, Y. Liu, X. Fan, L. Zhu, Y. Wang, H. Ma, X. Cao, Cryst. Eng. Comm., 2011, 13, 2863-2870.

[33] M. Ara, K. Wadumesthrige, T. Meng, S. O. Salley, K. Y. S. Ng, RSC Adv., 2014, 4, 2054020547.

[34] T. Zhu, J. S. Chen, X. W. Lou, J. Phys. Chem. C, 2011, 115, 9814-9820.

[35] V. Chandra, J. Park, Y. Chun, J. W. Lee, I.-C. Hwang, K. S. Kim, ACS Nano, 2010, 4, 39793986.

[36] B. Shen, W. Zhai, M. Tao, J. Ling, W. Zheng, ACS Appl. Mater. Interfaces, 2013, 5, 1138311391.

[37] M. Bayat, H. Yang, F. K. Ko, D. Michelson, A. Mei, Polymer, 2014, 55, 936-943.

[38] Y. Q. Wang, Q. Liu, Q. Qi, J. J. Ding, X. R. Gao, Y. Zhang, Y. M. Sun, Electrochim. Acta, 2013, 111, 31-40.

[39] R. M. Erb, J. Segmehl, M. Charilaou, J. F. Loffler, A. R. Studart, Soft Matter, 2012, 8, 76047609.

[40]H. C. Berg, Random Walks in Biology. 1993: Princeton University Press.

[41] S. Chatterjee, F. Nafezarefi, N. H. Tai, L. Schlagenhauf, F. A. Nüesch, B. T. T. Chu, Carbon, 2012, 50, 5380-5386.

[42] R. B. Ladani, S. Wu, A. J. Kinloch, K. Ghorbani, J. Zhang, A. P. Mouritz, C. H. Wang, Mater. Design, 2016,

[43] J. J. Jia, X. Y. Sun, X. Y. Lin, X. Shen, Y. W. Mai, J. K. Kim, ACS Nano, 2014, 8, 57745783.

[44] X. Wang, J. Jin, M. Song, Carbon, 2013, 65, 324-333.

[45] S. Chandrasekaran, N. Sato, F. Tolle, R. Mulhaupt, B. Fiedler, K. Schulte, Compos. Sci. Technol., 2014, 97, 90-99.

[46] S. Chandrasekaran, C. Seidel, K. Schulte, Eur. Polym. J., 2013, 49, 3878-3888.

[47] D. R. Bortz, E. G. Heras, I. Martin-Gullon, Macromolecules, 2011, 45, 238-245.

[48] I. Zaman, T. T. Phan, H.-C. Kuan, Q. Meng, L. T. Bao La, L. Luong, O. Youssf, J. Ma, Polymer, 2011, 52, 1603-1611.

[49] J. Ma, Q. S. Meng, A. Michelmore, N. Kawashima, Z. Izzuddin, C. Bengtsson, H. C. Kuan, J. Mater. Chem. A, 2013, 1, 4255-4264. 
[50] Y. T. Park, Y. Qian, C. Chan, T. Suh, M. G. Nejhad, C. W. Macosko, A. Stein, Adv. Funct. Mater, 2014, 25, 575-585.

[51] M. A. Rafiee, J. Rafiee, I. Srivastava, Z. Wang, H. Song, Z.-Z. Yu, N. Koratkar, Small, 2010, 6, 179-183.

[52] F. H. Gojny, M. H. G. Wichmann, B. Fiedler, I. A. Kinloch, W. Bauhofer, A. H. Windle, K. Schulte, Polymer, 2006, 47, 2036-2045.

[53] M. H. Al-Saleh, U. Sundararaj, Carbon, 2009, 47, $2-22$.

[54] W. L. Song, X. T. Guan, L. Z. Fan, W. Q. Cao, C. Y. Wang, Q. L. Zhao, M. S. Cao, J. Mater. Chem. A, 2015, 3, 2097-2107.

[55] E. V. Kuvardina, L. A. Novokshonova, S. M. Lomakin, S. A. Timan, I. A. Tchmutin, J. Appl. Polym. Sci., 2013, 128, 1417-1424. 